\title{
Association of air pollution with the risk of initial outpatient visits for tuberculosis in Wuhan, China
}

Man $\mathrm{Xu}{ }^{\mathrm{a}}$, Jiaqiang Liao ${ }^{\text {a }}$, Yuehua Li ${ }^{\mathrm{b}}$, Ping Yin ${ }^{\mathrm{c}}$, Jian Hou ${ }^{\mathrm{d}}$,Yun Zhou ${ }^{\mathrm{a}}$, Jiao Huang c, Bing Liu ${ }^{\mathrm{e}}$, Ruoling Chen ${ }^{\mathrm{f}}$, Li Ke ${ }^{\mathrm{e}}$, Nili Ren ${ }^{\mathrm{g}}$, Ping $\mathrm{Hu}^{\mathrm{a}}{ }^{*}$

${ }^{a}$ Key Laboratory of Environment and Health (HUST), Ministry of Education \&Ministry of Environmental Protection, and State Key Laboratory of Environmental Health (Incubation), School of Public Health, Tongji Medical College, Huazhong University of Science and Technology, Wuhan, 430030, Hubei, China

${ }^{b}$ Department of Tuberculosis Prevention, Wuhan Pulmonary Hospital, Wuhan, 430030, Hubei, China

${ }^{\mathrm{c}}$ Department of Epidemiology and Biostatistics and State Key Laboratory of Environment Health, Huazhong University of Science and Technology, Wuhan, 430030, Hubei, China

${ }^{\mathrm{d}}$ Department of Epidemiology and Biostatistics, College of Public Health, Zhengzhou University, Zhengzhou, Henan, China. ${ }^{e}$ Center of Health Administration and Development Studies, Hubei University of Medicine, Shiyan, Hubei, China

${ }^{\mathrm{f}}$ Faculty of Education, Health and Wellbeing, University of Wolverhampton, Wolverhampton, United Kingdom

g Medical Records Department, Wuhan Pulmonary Hospital, Wuhan, 430030, Hubei, China

${ }^{*}$ Corresponding author at: School of Public Health, Tongji Medical College, Huazhong University of Science and Technology, 13 Hangkong Road, Qiaokou District, Wuhan,430030, Hubei, China.

E-mail:pinghu@hust.edu.cn (Ping Hu); Telephone number:+ 8613476847682

Declarations of interest: None.

Words count :3919 


\section{ABSTRACT}

Objectives: Previous studies suggested the association of air pollution with initial Mycobacterium tuberculosis infection and the disease development. However, few studies have been conducted on air pollution and initial TB consults using short-interval data. We investigated the weekly association between air pollution and initial TB outpatient visits.

Methods: We used a Poisson regression model combined with a distributed lag nonlinear model to conduct a time-series study with weekly air pollution data and TB cases during 2014-2017 in Wuhan, China.

Results: A $10 \mu \mathrm{g} / \mathrm{m}^{3}$ increase in $\mathrm{NO}_{2}$ was associated with $11.74 \%$ (95\% CI: 0.70-23.98, lag 0-1 weeks), 21.45\% (1.44-45.41, lag 0-2) and 12.8\% (0.97-26.02, lag 0 -1) increase in initial TB consults among all TB patients, old patients ( $\geq 60$ years old) and male ones, respectively. A $10 \mu \mathrm{g} / \mathrm{m}^{3}$ increase in $\mathrm{SO}_{2}$ was associated with $-22.23 \%$ (-39.23 to -0.49 , lag $0-16),-28.65 \%$ (-44.3 to -8.58 , lag $0-16)$, -23.85 (-41.79 to -0.37 , lag 0-8), and $-23.82 \%$ ( $95 \%$ CI: -41.31 to -1.11 , lag $0-16$ ) increase in initial TB consults among the total, young (aged 15-59 years old), old and male patients, respectively. In old patients, a $0.1 \mathrm{mg} / \mathrm{m}^{3}$ increase in CO and a $10 \mu \mathrm{g} / \mathrm{m}^{3}$ increase in $\mathrm{PM}_{2.5}$ were separately associated with $42.32 \%(1.16-100.22$, lag $0-16)$ and $17.38 \%$ (0.28-37.38, lag 0-16) increases in TB consults.

Conclusion: Our study first highlighted the importance of weekly association between air pollution and the risk of initial TB consults, which is helpful for the arrangements of TB screening and medical assistance. 
Key words: Tuberculosis; Initial outpatient visits; Air pollution 


\section{Key messages}

\section{What is already known about this subject?}

Previous epidemiological and toxicological studies have revealed the association between ambient air pollution and the development of Mycobacterium tuberculosis infection. Data is lacking on the association between air pollution and initial TB outpatient visits with short-interval data.

\section{What are the new findings?}

$>$ Our study revealed that the risk of initial TB consults was positively associated with increased levels of $\mathrm{PM}_{2.5}, \mathrm{CO}$ and $\mathrm{NO}_{2}$ and was inversely associated with increased level of $\mathrm{SO}_{2}$ over lagged 16 weeks.

$>$ Old patients were sensitive to $\mathrm{PM}_{2.5}, \mathrm{CO}, \mathrm{NO}_{2}$ and $\mathrm{SO}_{2}$ and the male ones were sensitive to $\mathrm{NO}_{2}$ and $\mathrm{SO}_{2}$ with significant lag effects at various lag weeks.

\section{How might this impact on policy or clinical practice in the foreseeable future?}

$>$ The weekly lag effects of air pollution on TB consults have important implication for TB prevention and control in population. It will help policymakers improve TB screening strategies on high polluted period and offer more TB medical assistance in high polluted areas. 


\section{INTRODUCTION}

Tuberculosis (TB) has become the world's ninth leading cause of death, and continues to pose great threats to human health. ${ }^{1}$ China is among the global top 22 high-TB burden countries, and has the third largest number of TB patients in the world. ${ }^{1}$ TB is caused by the bacterium Mycobacterium tuberculosis (M.tb). Individuals with suppressed host immune system conditions, such as human immunodeficiency virus pandemic, diabetes and end-stage renal failure, were particularly susceptible to TB. ${ }^{2}$ In recent years, worldwide attention has increasingly extended to the association of ambient air pollution with TB cases.

A majority of individual- and population-based studies reported the association of TB cases with long-term air pollution exposure. In view of individual two-year average exposure of air pollution, a nested case-control study in Northern California and a cohort study of Taiwan residents both revealed a positive correlation of nitrogen dioxide $\left(\mathrm{NO}_{2}\right)$ with TB incidence. ${ }^{34}$ Ecological studies also showed the associations between annual average exposure of ambient air pollution with $\mathrm{TB} .{ }^{5}{ }^{6}$ A study in North Carolina suggested that exposure of particulate matter (PM) potentially increased the susceptibility to TB development. ${ }^{5}$ A study conducted by Hwang SS et al ${ }^{6}$ in South Korea found a positive association of sulfur dioxide $\left(\mathrm{SO}_{2}\right)$ with TB incidence. However, there are less investigation on the association of air pollution with reported TB cases using empirical and short-interval data. Only in most recent years, a couple of studies were undertaken to examine the association. ${ }^{7-9}$ Analyzing monthly data, You et al ${ }^{7}$ observed a stable link between incremental aerodynamic 
diameter of $\leq 2.5 \mu \mathrm{m}\left(\mathrm{PM}_{2.5}\right)$ concentration and increase in TB cases. Using daily data, Zhu et al ${ }^{8}$ found that increased level of $\mathrm{NO}_{2}$ and $\mathrm{SO}_{2}$ positively and independently correlated with newly reported TB cases, while Ge's group reported an inverse association of $\mathrm{SO}_{2}$ exposure with initial TB outpatient visits. ${ }^{9}$

The current epidemiological studies have suggested associations between air pollution and initial M.tb infection and disease development. However, relevant research on the impact of incremental level of air pollution on initial TB outpatient visits using short-interval data is still lacking. Given that TB patients are often accompanied by chronic symptoms for several weeks before their initial outpatient visits 1011 and using relevant data at the level of a month could not distinguish lag-specific effects from week to week , we aimed to explore whether weekly (7 days) exposure to $\mathrm{PM}_{10}, \mathrm{PM}_{2.5}, \mathrm{SO}_{2}, \mathrm{NO}_{2}$ and $\mathrm{CO}$ was associated with the risk of weekly TB cases for initial outpatient visits in Wuhan, to elucidate the risk of TB consults caused by fluctuations of air pollution concentrations.

\section{MATERIALS AND METHODS}

\section{Study area}

Wuhan (center: $114.3^{\circ} \mathrm{E}, 30.6^{\circ} \mathrm{N}$ ), the capital of Hubei Province, is the largest city in Central China and has moist subtropical monsoon climate.It is located on the eastern part of the Jianghan Plain, middle and lower reaches of the Yangtze River, and covers a total area of 8494.41 square kilometers with a permanent population of 10.914 million at the end of 2017. ${ }^{12}$ 


\section{Data on TB outpatients}

Daily cases of newly diagnosed TB in Wuhan from year 2014 to 2017 were obtained from online national infectious disease reporting system, which was offered by Wuhan Tuberculosis Institution. We also collected demographic information of each TB case, including age, sex and dates of initial TB outpatient visits. In practice, it is difficult to distinguish whether newly diagnosed TB cases were caused by initial infection or reactivated via endogenous factors after some weeks or years. ${ }^{8}$ Thus, the active TB cases in this study included newly infected cases and reactivated TB cases.

\section{Air pollution and climate data}

Daily average values of air pollution were obtained from China's National Urban Air Quality Real-time Publishing Platform ( http://106.37.208.233:20035 ), including $\mathrm{PM}_{10}, \mathrm{PM}_{2.5}, \mathrm{SO}_{2}, \mathrm{NO}_{2}$ and $\mathrm{CO}$. Meteorological parameters, including daily mean temperature, relative humidity, air pressure, rainfall, wind speed and duration of sunshine, were derived from China Meteorological Data Sharing Service System (http://cdc.cma.gov.cn).The locations of air quality monitoring stations and meteorological monitoring stations in Wuhan were shown on a map (eFigure 1). The weekly (7 days) average values of air pollution concentrations, meteorological measurements and weekly total number of TB cases of the whole city were calculated to examine the effects of air pollution on initial TB consults.

\section{Distributed lag nonlinear model (DLNM)}

As distributed lag nonlinear model (DLNM) can reveal the additional lag dimension of the exposure-response relationship, ${ }^{13}$ we fitted a DLNM to assess 
non-linear exposure-response relationship and lag effects of air pollution on the risk of initial TB consults. Suppose that $Y_{t}$, denotes the number of TB cases of the whole city at calendar time ( week ) $t$, and follows a Poisson distribution by $Y_{t} \mid \mu_{t} \sim \operatorname{POI}\left(\mu_{t}\right)$, where $\mu_{t}$ is the expected value of $Y_{t}$. Hence, a log-linear Poisson model which allows for overdispersion to combine a DLNM was applied. The single-pollutant model specifications used for estimating the relationship between pollution and initial TB cases at each single-week lag were as follows:

$$
\begin{aligned}
\log \left(\mu_{t}\right)= & \alpha+\beta A P_{t, l}+\mathrm{ns}(\text { temp,3) }+\mathrm{ns}(\text { humidity,3) }+\mathrm{ns}(\text { wind,3 })+\mathrm{ns}(\text { sunshine }, 3) \\
& +\lambda \text { year }+\mathrm{ns}(\text { time, } 6)+\delta \text { Spring-festival } \\
= & \alpha+\beta A P_{t, l}+\text { COVs }
\end{aligned}
$$

where $\alpha$ is the intercept, and $\mathrm{AP}_{t, l}$ is the cross-basis matrix by using a double natural cubic spline DLNM to each indicator of air pollution (AP); $\beta$ is the coefficient for $A P_{t, l}$, and $l$ is the maximum lag time up to 16 weeks; $\lambda$ and $\delta$ stand for coefficients of the dummy variables for year and the Spring Festival. The time spline function concerning the week is a natural cubic spline to account for seasonality with 6 degrees of freedom (df), which was determined based on the model fit using Akaike's information criterion (AIC). ${ }^{14}$ We fitted natural cubic splines with a priori 3 df to control for meteorological variables as covariates. ${ }^{8}$ The detailed descriptions for the choices of basis types, number and placement of knots and maximum lag weeks in this model and the selection for covariates were included in the supplementary materials (Section 2, including eTables 1-2, ).

We used excess risk (ER) estimates, which represented as the percentage change 
in initial TB outpatient visits per 10 units increase of air pollutants, to assess lag-specific and cumulative effects of air pollution on initial TB outpatient visits over lagged 16 weeks in the single-pollutant models. Then, stratification analysis by age and sex were performed to separately model the effects of air pollution in subgroups. Children $(<15$ years old ) were excluded from the subgroup analyses as the sample size of this group was only $140(0.6 \%)$, similar to that of $0.5 \%$ prevalence of the Ningbo study of China. ${ }^{9}$ In addition, as the two peak months of TB incidence in Wuhan are during March to April and August to September compared with the trough month ( December) of TB incidence, ${ }^{15}$ the analysis was stratified by “ peak season” (from March to August) and "trough season” (from September to February in next year) of TB incidence. Besides, we also used daily data to explore the association between air pollution and initial TB outpatient visits in the single-pollutant models in total population and subgroups stratified by age and sex, the detailed methods were described in the online supplementary files ( Section 5, including eTable 10 ) .Finally, we conducted several sensitivity analyses to assess the robustness of our main results by: (1) fitting two-pollutant models, (2) excluding 1,331(5.3\%) retreated TB, (3) changing the length of maximum lag weeks to 12 and 24 weeks in the DLNM, (4) using $7 \mathrm{df}$ and $4 \mathrm{df}$ in the splines on time and meteorological factors, respectively. The proportion of missing data in our study was $0.2 \%$ and missing values were interpolated using the averages of the data in the previous and the following days. Our data analysis was done using the dlnm packages in $\mathrm{R}$ (version 3.5.0). We mapped the positions of air pollutant and weather monitoring stations using ArcGIS (v.10.5) . 


\section{RESULTS}

\section{Basic characteristics of total TB patients, air pollutants and meteorological factors}

The distribution of weekly TB cases, air pollution and meteorological variables in Wuhan during 2014 to 2017 was summarized in Table 1. In total, there were 25,077 TB cases. Among them, 140 (0.6\%) were < 15 years old, 17,533 ( 69.9\%) were 15-59 years old, and 7,404 ( $29.5 \%$ ) were $\geqslant 60$ years old. There were 17,441( $69.5 \%$ ) male and 7,636 (30.5\%) female TB cases. More than 75\% observations of $\mathrm{PM}_{2.5}, \mathrm{PM}_{10}$ and $\mathrm{SO}_{2}$ were above $\mathrm{WHO}$ air quality guidelines and more than $50 \%$ observations of $\mathrm{NO}_{2}$ were above the guidelines. The temporal variations of total $\mathrm{TB}$ cases and averaged air pollution concentrations and meteorological measurements over the study period showed a clear seasonality ( eFigure 2-3). 
Table 1

Summarized statistics of weekly TB cases , air pollution and meteorological variables in Wuhan, 2014-2017( $\mathrm{n}=25,077)$.

\begin{tabular}{|c|c|c|c|c|c|c|}
\hline Variable & Mean \pm SD & P1 & $\mathbf{P} 25$ & P50 & P75 & P99 \\
\hline \multicolumn{7}{|l|}{ Weekly TB cases } \\
\hline Total & $120.0 \pm 25.5$ & 53 & 105 & 121 & 136 & 179 \\
\hline Male & $83.5 \pm 19.0$ & 30 & 72 & 83 & 95 & 127 \\
\hline Female & $36.5 \pm 9.5$ & 16 & 30 & 36 & 43 & 58 \\
\hline Children, 0-14 & $0.7 \pm 0.9$ & 0 & 0 & 0 & 1 & 3 \\
\hline Young, 15-59 & $83.9 \pm 18.4$ & 34 & 72 & 83 & 96 & 127 \\
\hline Middle and old, $\geq 60$ & $35.4 \pm 9.6$ & 12 & 31 & 35 & 41 & 62 \\
\hline \multicolumn{7}{|l|}{ Pollutant concentration } \\
\hline $\mathrm{PM}_{2.5}\left(\mu \mathrm{g} / \mathrm{m}^{3}\right)$ & $64.9 \pm 35.7$ & 17.0 & 41.0 & 56.0 & 84.0 & 178.6 \\
\hline $\mathrm{PM}_{10}\left(\mu \mathrm{g} / \mathrm{m}^{3}\right)$ & $101.2 \pm 40.6$ & 32.6 & 70.0 & 97.0 & 123.0 & 210.1 \\
\hline $\mathrm{SO}_{2}\left(\mu \mathrm{g} / \mathrm{m}^{3}\right)$ & $18.5 \pm 12.7$ & 4.0 & 9.0 & 16.0 & 23.0 & 71.9 \\
\hline $\mathrm{NO}_{2}\left(\mu \mathrm{g} / \mathrm{m}^{3}\right)$ & $49.7 \pm 15.4$ & 25.2 & 38.0 & 48.0 & 57.0 & 93.9 \\
\hline $\mathrm{CO}\left(\mathrm{mg} / \mathrm{m}^{3}\right)$ & $1.1 \pm 0.3$ & 0.6 & 0.9 & 1.0 & 1.2 & 2.2 \\
\hline \multicolumn{7}{|l|}{ Meteorology measure } \\
\hline Mean average temperature $\left({ }^{\circ} \mathrm{C}\right)$ & $17.3 \pm 8.5$ & 1.9 & 9.4 & 18.6 & 2.5 & 32.2 \\
\hline Relative humidity (\%) & $77.1 \pm 9.1$ & 55.1 & 71.0 & 78.0 & 85.0 & 94.0 \\
\hline Air pressure (hPa) & $1010.2 \pm 8.6$ & 996.7 & 1002.6 & 1010.6 & 1017.7 & 1025.6 \\
\hline wind velocity (m/s) & $2.0 \pm 0.4$ & 1.3 & 1.7 & 2.0 & 2.2 & 185.3 \\
\hline Rainfall (mm/week) & $3.9 \pm 5.8$ & 0 & 0.3 & 2.5 & 5.4 & 20.7 \\
\hline Duration of sunshine (hr/week) & $4.7 \pm 2.4$ & 0.1 & 3.0 & 4.5 & 6.3 & 11.0 \\
\hline
\end{tabular}

Note: SD: standard deviation; P1, P25, P50, P75, and P99 are the $1^{\text {st }}, 25^{\text {th }}, 50^{\text {th }}, 75^{\text {th }}$ and $99^{\text {th }}$ percentiles of variables, respectively. 


\section{Lag associations between air pollution and initial TB outpatient visits}

Lag-specific and cumulative ERs in initial outpatient TB cases for increased weekly concentrations of each air pollutant were shown for all ages combined over lag 0-16 weeks in single-pollutant models (Figure 1 and eTables 3-7). A $10 \mu \mathrm{g} / \mathrm{m}^{3}$ increase in $\mathrm{NO}_{2}$ was associated with $11.74 \%$ ( 95\% CI: 0.70-23.98, lag 0-1) increase in initial TB consults. And, a $10 \mu \mathrm{g} / \mathrm{m}^{3}$ increase in $\mathrm{SO}_{2}$ was associated with $-19.00 \%$ (95\% CI: -34.06 to -0.49 , lag $0-9$ ) to $-22.23 \%$ ( $95 \%$ CI: -39.23 to -0.49 , lag $0-16$ ) increase in initial TB outpatient visits. There was no evidence on associations of $\mathrm{PM}_{10}$, $\mathrm{PM}_{2.5}$ or $\mathrm{CO}$ with the risk of initial TB consults in the overall population.

Upon stratification by age, obviously different estimated exposure-response curves appeared between young (aged 15-59 years old) and old ( $\geq 60$ years old) patients ( Figure 2 and eTables 3-7). Among old patients, a $10 \mu \mathrm{g} / \mathrm{m}^{3}$ increase in $\mathrm{PM}_{2.5}$, a $10 \mu \mathrm{g} / \mathrm{m}^{3}$ increase in $\mathrm{NO}_{2}$ and a $0.1 \mathrm{mg} / \mathrm{m}^{3}$ increase in $\mathrm{CO}$ were associated with 17.38\% ( 95\% CI: 0.28, 37.38, lag 0-16) , 21.45\% ( 95\% CI: 1.44, 45.41, lag 0-2) and 23.37\% ( 95\% CI: 0.94, 50.8, lag 0-9) to 42.32\% ( 95\% CI: 1.16, 100.22, lag 0-16) increases in initial TB consults, respectively. Besides, cumulative ERs of $\mathrm{SO}_{2}$ were from $-18.4 \%$ ( $95 \%$ CI: $-32.32,-1.62$, lag $0-7$ ) to $-28.65 \%$ ( $95 \%$ CI: -44.32 to -8.58 , lag 0-16) among the young patients and $-22.83 \%$ ( $95 \%$ CI: -39.72 to -1.21 , lag 0-6) to -23.85 ( 95\% CI: -41.79 to -0.37 , lag 0-8) among the old patients.

Once stratified by gender, the pattern of association with $\mathrm{NO}_{2}$ and $\mathrm{SO}_{2}$ previously observed in the whole TB patients only persisted in the male ones ( Figure 3 and 
eTables 3-7). $\mathrm{NO}_{2}$ had an immediate effect on TB cases at the same week with $12.8 \%$ ( 95\% CI: 0.97, 26.02, lag 0-1) increase in initial TB consults. In addition, reduced risks of $\mathrm{SO}_{2}$ on TB cases were from $-19.21 \%$ ( $95 \% \mathrm{CI}$ : -33.66 to -1.6 , lag $0-7$ ) to $-23.82 \%$ ( 95\% CI: -41.31 to -1.11 , lag 0-16).

When stratified by the season of TB incidence (eFigure 4 and eTables 8-9), during September to February in next year, increased CO was positively associated with the risk of initial TB outpatient visits with cumulative ERs lasting from $44.54 \%$ (95\%CI: 16.06, 80.02, lag 0-1) to 201.9\% ( 95\%CI: 29.42, 604.28, lag 0-16). Besides, increased $\mathrm{PM}_{2.5}$ was associated with 4.64\% (95\%CI: 0.22, 9.26, lag 0) increase in initial TB outpatient visits. But no significant cumulative effects of all the air pollutants were found during March to August, despite lag-specific effects of $\mathrm{PM}_{10}$ at lag 6-8 weeks and $\mathrm{NO}_{2}$ at lag 6 week.

In addition, we analyzed the effects of air pollution on TB outpatient visits at daily level over lag 0-7, lag 0-14 and lag 0-21 days (eFigures 5-9), we only found that increased $\mathrm{PM}_{2.5}$ was associated with reduced risk of initial TB consults over lag 0-2 days among male patients, and increased $\mathrm{SO}_{2}$ was associated with increased risk of initial TB consults over lag 7-14 days. There was no evidence on associations of $\mathrm{PM}_{10}$, $\mathrm{NO}_{2}$ or $\mathrm{CO}$ with the risk of initial TB consults in the total population and subgroups.

\section{Sensitivity analyses}

The reasons and detailed results for sensitivity analyses were shown in the supplementary materials. In brief, despite some changes occurred in certain subgroups or pollutants, the main results were not substantially changed, when conducting the 
two-pollutant models (eFigures 10-14), when excluding retreated TB cases (eFigures 15-17), and when changing the max lags (eFigure 18) and dfs for smoother time and meteorological factors (eFigures 19-20).

\section{DISCUSSION}

\section{Lag associations between air pollution and initial TB outpatient visits}

Due to severe weather conditions and increased local emissions especially from its complex regional transport processes and recent rapid urbanization construction in Wuhan, air pollution in this city is getting quite serious. ${ }^{16}{ }^{17}$ This study conducted in Wuhan, to our knowledge, was the first time to estimate the weekly lag associations of conventional air pollutants with the risk of initial TB outpatient visits in the world. In our study, the risk of total initial TB outpatient visits was positively associated with $\mathrm{NO}_{2}$ but inversely associated with $\mathrm{SO}_{2}$. Upon stratification by age, we observed positive associations of initial $\mathrm{TB}$ consults with $\mathrm{PM}_{2.5}, \mathrm{NO}_{2}$, and $\mathrm{CO}$ among old patients and inverse associations of initial $\mathrm{TB}$ consults with $\mathrm{SO}_{2}$ among both young and old ones. When stratified by sex, the associations of $\mathrm{SO}_{2}$ and $\mathrm{NO}_{2}$ previously shown in the total patients were only observed in the male ones. Given that our study was based on air pollution exposure at weekly level rather than acute exposure ${ }^{89}$ or long-term exposure ${ }^{34}$ reported in other studies, the results mainly revealed some susceptible populations for the risk of initial TB consults with the exposure to air pollutants at fluctuated levels, which, to some extent, implied sub-acute impact of air pollutants on the risk of initial TB consults. Furthermore, the results analyzed using 
data at daily level also provided some evidences, as the strength of its correlation signal was weak in the daily DLNM.

As TB incubation period varies from weeks to years, ${ }^{18}$ it’s difficult to distinguish the time of TB onset. However, there is a time interval between onset of symptoms and initial TB consults, defined as health-seeking delay, the medians of which reported in China were 2.5-7.5 weeks. ${ }^{10} 11$ Accordingly, the lag association between increased air pollution and subsequent initial TB consults reflected two stages: the time required for health-seeking delay and the development of M.tb growth (the partial incubation period of TB). Furthermore, as the early M.tb infection and its subsequent development are basically regulated by initial interaction between M.tb and host immune response, ${ }^{19}$ significant short-lag effects of $\mathrm{PM}_{2.5}$ (lag 1-2 weeks), $\mathrm{NO}_{2}$ ( lag 0-1 weeks) and CO (lag 3-5 weeks) observed in the subgroups may mainly refer to the former stage. During the stage, increased levels of air pollution may play a role in promoting inflammatory response in the development of M.tb infection, thus leading to earlier patients’ initial health-seeking.

We found that $\mathrm{NO}_{2}$ was strongly associated with initial TB visits over lag 0-1 weeks. Similarly, other studies have previously reported significant short-interval lag effects of $\mathrm{NO}_{2}$ in TB outcomes, such as increased risk of active TB over lag 0-2 days ${ }^{8}$ and higher odds ratios for TB-related hospital admission at lag $1.5-2$ weeks, ${ }^{20}$ which indicate that $\mathrm{NO}_{2}$ might play a “priming” role in patients' initial health-seeking due to TB symptoms. It is consistent with previous medical research, in which outdoor $\mathrm{NO}_{2}$ was demonstrated to impair airway mucous membranes and mucociliary clearance, 
and may facilitate access of inhaled exogenous allergen into respiratory immune system and cause respiratory symptoms. ${ }^{21}$

Despite the lag-specific effects of increased $\mathrm{PM}_{2.5}$ occurred in the old at lag 1-2 weeks, their significant cumulative effects could last for four months. You et al ${ }^{7}$ also revealed a stable association between increased $\mathrm{PM}_{2.5}$ during winter and increased number of TB cases in the subsequent spring or summer in Beijing and Hong Kong. Some toxicological experiments indicated that PM could suppress respiratory epithelium innate immunity, ${ }^{22-24}$ which may increase host's susceptibility to early M.tb infection and TB progression. But we did not find significant association between $\mathrm{PM}_{10}$ and TB outcome, which is consistent with some other studies. ${ }^{34620}$ As particle size was reported to inversely correlate with PM toxicity in producing pulmonary inflammatory response, ${ }^{25} \mathrm{PM}_{10}$ might be too coarse an indicator to detect the association between PM toxicity and TB visits.

Our study found positive associations between increased level of CO and initial TB consults lasted from over lag 0-9 weeks to lag 0-16 weeks. No previous study has found significant association between short- or long-term exposure of CO and TB outcomes, except that Smith et al ${ }^{4}$ found a significant positive association between long-term exposure of $\mathrm{CO}$ and $\mathrm{TB}$ incidence in Northern California only in the single-pollutant model. The potential mechanisms between short- or long-term exposure of $\mathrm{CO}$ and $\mathrm{TB}$ outcomes is still not clear. But an experiment in mice discovered a gradually decreased mRNA expression of several proinflammatory cytokines and cell signaling enzymes that implicated in controlling M.tb infection 
when mice were exposed to diesel exhaust (measured including CO) from one to six months. ${ }^{26}$

We observed increased $\mathrm{SO}_{2}$ was positively associated with increased risk of initial TB consults at lag 2 week in those $\geqslant 60$ years old with no significant cumulative effects. But during various lagged weeks we also found inverse associations of $\mathrm{SO}_{2}$ with initial $\mathrm{TB}$ outpatient visits among young patients, old patients and male ones, apart from the total patients. The adverse effects of $\mathrm{SO}_{2}$ may be related to its toxic effects by enhancing the inflammatory reaction in lungs. ${ }^{27}$ Previous studies showed positive associations of daily exposure to $\mathrm{SO}_{2}$ with $\mathrm{TB},{ }^{6}$ but a study at Ningbo in China also showed inverse associations between $\mathrm{SO}_{2}$ and the risk of initial TB outpatient visits using daily data. ${ }^{9}$ Despite its toxic effects of $\mathrm{SO}_{2}$ on many organs, its protective biological effects on TB have been observed in animal and cell experiments. In male mice, $\mathrm{SO}_{2}$ inhalation at $14 \mathrm{mg} / \mathrm{m}^{3}$ (5 ppm) increased levels of IL-6 and TNF- $\alpha$ in lungs as well as the level of TNF- $\alpha$ in serum. ${ }^{28}$ IL-6 and TNF- $\alpha$ are involved in immune cell differentiation and chemotaxis and granuloma formation, which is critical to control M.tb infection. ${ }^{19}$ Furthermore, vitro experiments have shown that exogenous $\mathrm{SO}_{2}$, by $\mathrm{SO}_{2}$-releasing molecules, has a potency of inhibiting the growth of $M . t b$ higher than first-line antitubercular agent isoniazide. ${ }^{29}$ Due to inconsistent findings of the effects of $\mathrm{SO}_{2}$ on $\mathrm{TB}$ in population-based studies, more studies are required to clarify the effects.

Old patients were more susceptible to the exposure of $\mathrm{PM}_{2.5}, \mathrm{NO}_{2}$ and $\mathrm{CO}$ in the increased risk of initial TB consults. One plausible reason is that older people had a 
higher TB incidence contributed by reactivation of TB infection obtained decades earlier, ${ }^{30}$ and elevated concentrations of those air pollutants may aggravate their respiratory inflammation. Moreover, their particular susceptibility to TB development are potentially linked with low-grade systemic inflammation widespread among this group. ${ }^{31}$

We also found the males had greater sensitivity to increased risk of initial TB consults when exposed to $\mathrm{NO}_{2}$ at a higher level, which may be attributable to their social and biological gender-related factors. For example, males are more likely to work in the circumstances such as chemical plants, coal miners and roads, which may expose men to more source of air pollutants. ${ }^{32}$ Furthermore, male sex hormones may play a part in their lower resistance to M.tb infection, as the stimulated secretion of a series of cytokines, such as TNF, IL-2 or IL-10, could be inhibited by testosterone but enhanced by $17 \beta$-estradiol (E2) and downstream estrogens. ${ }^{33}$ Additionally, in China there is a much higher prevalence of smoking in men (68.2\%) than women (11.7\%). ${ }^{34}$ Some evidence has shown that smoking increased risk of developing TB. ${ }^{35} 36$ Smoking and air pollution may have interactive effects on TB incidence to some extent as nicotine or cigarette smoke could inhibit T cell-mediated immunity, ${ }^{37}$ which may explain males' higher susceptibility to the progression to TB. But the potential mechanism why males had greater sensitivity to decreased risk of initial TB consults when exposed to higher level of $\mathrm{SO}_{2}$ needs further research.

In addition, during September to February in the next year, significant positive association of increased risk of initial TB outpatient visits with increased $\mathrm{CO}$ and 
$\mathrm{PM}_{2.5}$ were separately observed, especially the apparent effects of CO. They were mainly attributed to the stimulative effect to the respiratory system by $\mathrm{CO}$ and $\mathrm{PM}_{2.5}$ in high concentrations during this period,since the mean concentrations of $\mathrm{CO}$ and $\mathrm{PM}_{2.5}$ were separately $1.24 \mathrm{mg} / \mathrm{m}^{3}$ and $79.65 \mu \mathrm{g} / \mathrm{m}^{3}$ during this peroid whereas those of CO and PM2.5 were $0.95 \mathrm{mg} / \mathrm{m}^{3}$ and $49.49 \mu \mathrm{g} / \mathrm{m}^{3}$ during March to August, respectively. Additionally, meteorological factors, such as temperature and humidity, were known to affect air pollution concentrations.

\section{Implications of public health}

In summary, we applied an ecological design discovering associations between incremental level of some air pollutants and the risk of initial TB outpatient visits instead of exploring a causal relationship. The effects of weekly increased level of air pollution on the risk of initial TB consults may be underestimated since the maximum lag period can be as long as four months, and it also warrants caution to interpret effects of air pollution on TB incidence. Using a DLNM at daily level seems to lose more information than that at weekly level, as we did not observe acute effects of air pollutants on the risk of initial TB consults and there is a limit in max lag days in DLNM using daily data. The risk prediction models of initial TB consults by assessing current status of air pollution is useful for public health personnel to improve TB screening strategies on high polluted period and offer more TB medical assistance in high polluted areas. In addition, reducing levels of $\mathrm{PM}_{2.5}, \mathrm{NO}_{2}$ and $\mathrm{CO}$ in air could also help TB prevention and control in population. 


\section{Strengths and limitations}

A key advance of this study is that we used weekly data to explore effects of air pollution, which will help further understand impacts of fluctuated levels of air pollution in the process of outpatient visits for TB patients over 4 months. Secondly, DLNM can simultaneously represent the exposure-response relationship with the predictor variable and the lag-response relationship with the lag time, ${ }^{13}$ instead of only estimating effects of a single lag or several days at a particular lag as in other models. ${ }^{38}{ }^{39}$ However, several limitations of our study should be addressed. Firstly, our study was limited to only one city with relatively shorter research periods, which may limit the generalization of our results to other cities. Considering Wuhan is the largest city in Central China, where outdoor air pollution was at an intermediate or upper level, and its epidemic situation of TB was close to the national average level, ${ }^{40}$ our study can be representative of some cities in China. Furthermore, larger studies including different parts of China with longer periods in the future are needed. Secondly, our analyses were based on data at an aggregate level and failed to get information on personal risk factors for stratification, which implicates the potential to introduce information bias and confounders to our results.

\section{CONCLUSIONS}

Our findings interpreted the associations of air pollutants including $\mathrm{PM}_{2.5}, \mathrm{CO}$, $\mathrm{NO}_{2}$ and $\mathrm{SO}_{2}$ with the risk of initial TB consults over lagged 16 weeks with the DLNM using weekly data. Old patients were sensitive to $\mathrm{PM}_{2.5}, \mathrm{CO}$, and $\mathrm{NO}_{2}$ and 
male ones were sensitive to $\mathrm{NO}_{2}$ and $\mathrm{SO}_{2}$ with significant lag effects at various lag weeks. The findings implied effects of air pollution on initial TB consults may be involved in the development of M.tb growth and patient health-seeking delay. 
Acknowledgment We appreciated Professor Songlin Yu, who was retired from School of Public Health, Tongji Medical College, Huazhong University of Science and Technology, offered statistical guidance.

Contributors MX, JL, NR, YL and PH: study concept and design; NR and YL:data collection and supervision; MX: drafting of the manuscript; MX and JL: analysis and interpretation of data; NR, YL, JH, YZ, BL, LK, RC and PH: involved in the critical revision of the manuscript for important intellectual content; PY, YZ and JH: statistical analysis; RC: polishing the language.

Funding This research did not receive any specific grant from funding agencies in the public, commercial, or not-for-profit sectors.

\section{Conflict of interest None.}

Patient consent None. All patients' personal data acquired were anonymous and did not contain any identifiable information, thus did not need ethical approval.

Ethics approval None. All patients' personal data acquired were anonymous and did not contain any identifiable information, thus did not need patient consent.

Data sharing No additional data are available.

\section{REFERENCES}

1 World Health Organization. Global tuberculosis report 2017. http://www.who.int/tb/publications/global_report/en/_accessed 1 May 2018).

2 Ankrah AO, Glaudemans AWJM, Maes A , et al.Tuberculosis. Semin Nucl Med 2018;48:108-30. 
3 Lai TC, Chiang CY, Wu CF, et al. Ambient air pollution and risk of tuberculosis: acohort study. Occup Environ Med 2016;73:56-61.

4 Smith GS, Van Den Eeden SK, Garcia C , et al. Air Pollution and Pulmonary Tuberculosis: A Nested Case-Control Study among Members of a Northern California Health Plan. Environ Health Perspect 2016;124:761-8.

5 Smith GS, Schoenbach VJ, Richardson DB, et al. Particulate air pollution and susceptibility to the development of pulmonary tuberculosis disease in North Carolina: an ecological study. Int J Environ Health Res 2014;24:103-12.

6 Hwang SS, Kang S, Lee JY, et al. Impact of outdoor air pollution on the incidence of tuberculosis in the Seoul metropolitan area, South Korea. Korean $J$ Intern Med 2014;29:183-90.

7 You S, Tong YW, Neoh KG, et al.On the association between outdoor PM2.5 concentration and the seasonality of tuberculosis for Beijing and Hong Kong. Environ Pollut 2016;218:1170-79.

8 Zhu S, Xia L, Wu J , et al. Ambient air pollutants are associated with newly diagnosed tuberculosis: A time-series study in Chengdu, China. Sci Total Environ 2018;631-632:47-55.

9 Ge E, Fan M, Qiu H , et al. Ambient sulfur dioxide levels associated with reduced risk of initial outpatient visits for tuberculosis: A population based time series analysis. Environ Pollut 2017;228:408-15.

10 Shi JS, Jia CX, Zhang HM. The research on detection delay and patient's pelay Influencing factors of rural new smear positive pulmonary TB of Ji'ning City. 
Preventive Medicine Tribune 2008;14:621-22 (Chinese).

$11 \mathrm{Li} \mathrm{YH.Current} \mathrm{situation} \mathrm{and} \mathrm{factors} \mathrm{affecting} \mathrm{healthseeking} \mathrm{delay} \mathrm{in} \mathrm{tuberculosis}$ in residents and floating population in sample counties of global fund project,Shandong Province. Shandong University Master‘s Thesis. 2011.

12 Wuhan bureau of statistics. Wuhan national economic and social development statistical communique in 2017. http://www.whtj.gov.cn/details.aspx?id=3957 (accessed 19 March 2018).

13 Gasparrini A, Armstrong B, Kenward MG. Distributed lag non-linear models. Stat Med 2010;29:2224-34.

14 Peng RD, Dominici F, Louis TA. Model Choice in Time Series Studies of Air Pollution and Mortality. J R Statist Soc 2006; 169: 179-203.

15 Zhang ZB, Lu ZQ, Xie H, et al. [Seasonal variation and related influencing factors for tuberculosis]. Zhonghua Liu Xing Bing Xue Za Zhi 2016;37:1183-6.

$16 \mathrm{Lu} \mathrm{M}$, Tang X, Wang Z , et al. Source tagging modeling study of heavy haze episodes under complex regional transport processes over Wuhan megacity, Central China. Environ Pollut 2017;231:612-21.

17 Qian Z, Liang S, Yang S , et al. Ambient air pollution and preterm birth: A prospective birth cohort study in Wuhan, China. Int J Hyg Environ Health 2016;219:195-203.

18 Rangaka MX, Cavalcante SC, Marais BJ , et al. Controlling the seedbeds of tuberculosis: diagnosis and treatment of tuberculosis infection. Lancet 2015;386:2344-53. 
19 Sasindran SJ, Torrelles JB. Mycobacterium Tuberculosis Infection and Inflammation: what is Beneficial for the Host and for the Bacterium? Front Microbiol 2011; 2:1-16.

20 Alvaro-Meca A, Diaz A, de Miguel Diez J ,et al. Environmental Factors Related to Pulmonary Tuberculosis in HIV-Infected Patients in the Combined Antiretroviral Therapy (cART) Era. Plos One 2016;11:e0165944.

21 D'Amato G, Cecchi L, D'Amato M, et al. Urban air pollution and climate change as environmental risk factors of respiratory allergy: an update. J Investig Allergol Clin Immunol 2010;20:95-102.

22 Rivas-Santiago B, Sada E, Tsutsumi V, et al. $\beta$-Defensin Gene Expression during the Course of Experimental Tuberculosis Infection. $J$ Infect Dis 2006;194:697-701.

23 Rivas-Santiago CE, Sarkar S, Cantarella Pt ,et al. Air pollution particulate matter alters antimycobacterial respiratory epithelium innate immunity. Infect Immun 2015;83:2507-17.

24 Schwander S, Cantarella P, Sarkar S, et al. Respiratory epithelial cell innate immunity against Mycobacterium tuberculosis is deregulated by air pollution particulate matter (PM). J Immunol 2014, 192 (Suppl 1)186.18.

25 Gillespie P, Tajuba J, Lippmann M, et al. Particulate matter neurotoxicity in culture is size-dependent. Neurotoxicology 2013;36:112-7.

26 Hiramatsu K, Saito Y, Sakakibara K, et al. The effects of inhalation of diesel exhaust on murine mycobacterial infection. Exp Lung Res 2005;31:405-15. 
27 Yun Y, Li HY, Li GK, et al. SO2 inhalation modulates the expression of apoptosis-related genes in rat hippocampus via its derivatives in vivo. Inhalation Toxicology 2010;22:919-29.

28 Meng Z, Liu Y, Wu D. Effect of sulfur dioxide inhalation on cytokine levels in lungs and serum of mice. Inhalation Toxicology 2004;17:303-7.

29 Malwal SR, Sriram D, Yogeeswari P, et al. Design, synthesis, and evaluation of thiol-activated sources of sulfur dioxide $(\mathrm{SO}(2))$ as antimycobacterial agents. $J$ Med Chem 2012;55:553-7.

30 Huynh GH, Klein DJ, Chin DP, et al. Tuberculosis control strategies to reach the 2035 global targets in China: the role of changing demographics and reactivation disease. BMC Med 2015;13:88.

31 Ault R, Dwivedi V, Koivisto E, et al. Altered monocyte phenotypes but not impaired peripheral $\mathrm{T}$ cell immunity may explain susceptibility of the elderly to develop tuberculosis. Experimental Gerontology 2018;111:35-44.

32 Locke SJ, Colt JS, Stewart PA, et al. Identifying gender differences in reported occupational information from three US population-based case-control studies. Occup Environ Med 2014;71:855-64.

33 Janele D, Lang T, Capellino S, et al. Effects of testosterone, 17 beta-estradiol, and downstream estrogens on cytokine secretion from human leukocytes in the presence and absence of cortisol. Ann N Y Acad Sci 2010; 1069:168-82.

34 Hao W, Li LJ, Xiao SY, et al. The Gender Differences and Related Factors in Drinking and Smoking Behaviors among General Population of Two 
Communities in Hunan Province. Chinese Journal of Clinical Psychology 1994; 2: 90-94.

35 Rao VG, Gopi PG, Bhat J, et al. Selected risk factors associated with pulmonary tuberculosis among Saharia tribe of Madhya Pradesh, central India. European Journal of Public Health 2012;22:271-3.

36 Gajalakshmi V, Peto R. Smoking, drinking and incident tuberculosis in rural India: population-based case-control study. International Journal of Epidemiology 2009;38:1018-25.

37 Sopori ML, Kozak W, Savage SM, et al. Nicotine-induced modulation of T Cell function. Implications for inflammation and infection. Adv Exp Med Biol $1998 ; 437: 279-89$.

38 Dai X, He X, Zhou Z , et al. Short-term effects of air pollution on out-of-hospital cardiac arrest in Shenzhen, China. Int J Cardiol 2015;192:56-60.

39 Babalola O, Razzaque A, Bishai D. Temperature extremes and infant mortality in Bangladesh: Hotter months, lower mortality. PLoS One 2018;13:e0189252.

40 Wang JJ, Zhou ML, Duan QH, et al. The fifth tuberculosis epidemiological survey of Wuhan City in 2010. Chinese Journal of Disease Control \& Prevention 2014;18:326-29. 


\section{Supplementary Materials}

\section{Association of air pollution with increased risk of initial outpatient visits for tuberculosis in Wuhan, China}

Man $\mathrm{Xu}{ }^{\mathrm{a}}$, Jiaqiang Liao a, Yuehua Li ${ }^{\mathrm{b}}$, Ping Yin ${ }^{\mathrm{c}}$, Jian Hou ${ }^{\mathrm{d}}$, Yun Zhou ${ }^{\mathrm{a}}$, Jiao Huang ${ }^{\text {c }}$, Bing Liu ${ }^{\mathrm{e}}$, Ruoling Chen ${ }^{\mathrm{f}}$, Li Ke ${ }^{\mathrm{e}}, \mathrm{Nili}$ Ren ${ }^{\mathrm{g}}$, Ping $\mathrm{Hu}^{\mathrm{a}^{*}}$

${ }^{a}$ Key Laboratory of Environment and Health (HUST), Ministry of Education \&Ministry of Environmental Protection, and State Key Laboratory of Environmental Health (Incubation), School of Public Health, Tongji Medical College, Huazhong University of Science and Technology, Wuhan, 430030, Hubei, China

bDepartment of Tuberculosis Prevention, Wuhan Pulmonary Hospital, Wuhan, 430030, Hubei, China

${ }^{\mathrm{c}}$ Department of Epidemiology and Biostatistics and State Key Laboratory of Environment Health, Huazhong University of Science and Technology, Wuhan, 430030, Hubei, China ${ }^{\mathrm{d}}$ Department of Epidemiology and Biostatistics, College of Public Health, Zhengzhou University, Zhengzhou, Henan, China.

${ }^{\text {e}}$ Center of Health Administration and Development Studies, Hubei University of Medicine, Shiyan, Hubei, China

fFaculty of Education, Health and Wellbeing, University of Wolverhampton, Wolverhampton, United Kingdom

gMedical Records Department, Wuhan Pulmonary Hospital, Wuhan, 430030, Hubei, China

* Corresponding author at: School of Public Health, Tongji Medical College, Huazhong University of Science and Technology, 13 Hangkong Road, Qiaokou

District, Wuhan, 430030, Hubei, China.

E-mail:pinghu@hust.edu.cn ( Ping Hu); Telephone number:+ 8613476847682 


\section{Table of Contents}

\section{Section 1. Monitoring stations and trend plots}

eFigure 1. Wuhan city and the locations of air pollution and weather monitoring stations.

eFigure 2. Trend plot of weekly total TB cases and mean air pollution concentrations in Wuhan during the study period.

eFigure 3. Trend plot of weekly mean climate measures in Wuhan during the study period.

\section{Section 2. Distributed lag nonlinear model (DLNM) at weekly level}

eTable 1 Spearman's correlation coefficients between weekly air pollution and meteorological variables in Wuhan, 2014-2017.

eTable 2 Knots in the double natural cubic splines for the best model fitting in the distributed lag nonlinear model for each pollution model.

\section{Section 3. Single-pollutant models in total population and subgroups}

eTable 3 Lag-specific percentage changes (excess risk with 95\% confidence interval) in initial outpatient visits for TB per $10 \mu \mathrm{g} / \mathrm{m}^{3}$ increase in weekly mean concentrations of $\mathrm{PM}_{10}$ over lagged 16 weeks in single-pollutant models.

eTable 4 Lag-specific percentage changes (excess risk with 95\% confidence interval) in initial outpatient visits for TB per $10 \mu \mathrm{g} / \mathrm{m}^{3}$ increase in weekly mean concentrations of $\mathrm{PM}_{2.5}$ over lagged 16 weeks in single-pollutant models.

eTable 5 Lag-specific percentage changes (excess risk with 95\% confidence interval) in initial outpatient visits for TB per $10 \mu \mathrm{g} / \mathrm{m}^{3}$ increase in weekly mean concentrations of $\mathrm{SO}_{2}$ over lagged 16 weeks in single-pollutant models.

eTable 6 Lag-specific percentage changes (excess risk with 95\% confidence interval) in initial outpatient visits for TB per $10 \mu \mathrm{g} / \mathrm{m}^{3}$ increase in weekly mean concentrations of $\mathrm{NO}_{2}$ over lagged 16 weeks in single-pollutant models.

eTable 7 Lag-specific percentage changes (excess risk with 95\% confidence interval) in initial outpatient visits for TB per $10 \mu \mathrm{g} / \mathrm{m}^{3}$ increase in weekly mean concentrations of CO over lagged 16 weeks in single-pollutant models.

\section{Section 4. Analysis stratified by season}


eFigure 4. Lag-specific and cumulative excess risks (\%) in initial outpatient visits for TB per 10 units increase in weekly mean concentrations of air pollution over lagged 16 weeks in single-pollutant models stratified by the season of TB incidence.

eTable 8 Lag-specific percentage changes (excess risk with 95\% confidence interval) in initial outpatient visits for TB per 10 units increase in weekly mean concentrations of air pollution over lagged 16 weeks in single-pollutant models from March to August.

eTable 9 Lag-specific percentage changes (excess risk with 95\% confidence interval) in initial outpatient visits for TB per 10 units increase in weekly mean concentrations of air pollution over lagged 16 weeks in single-pollutant models from September to February in next year.

\section{Section 5. Analysis at daily level}

(1) Distributed lag nonlinear model (DLNM) at daily level

eTable 10 Spearman's correlation coefficients between daily air pollution and meteorological variables in Wuhan, 2014-2017.

(2) Single-pollutant models in total population and subgroups at daily level

eFigure 5. Lag-specific relative risks in initial outpatient visits for TB per $10 \mu \mathrm{g} / \mathrm{m}^{3}$ increase in weekly mean concentrations of $\mathrm{PM}_{10}$ over lagged 7, 14 and 21 days in single-pollutant models among all TB patients and subgroups stratified by age and sex.

eFigure 6. Lag-specific relative risks in initial outpatient visits for TB per $10 \mu \mathrm{g} / \mathrm{m}^{3}$ increase in weekly mean concentrations of $\mathrm{PM}_{2.5}$ over lagged 7, 14 and 21 days in single-pollutant models among all TB patients and subgroups stratified by age and sex.

eFigure 7. Lag-specific relative risks in initial outpatient visits for TB per $10 \mu \mathrm{g} / \mathrm{m}^{3}$ increase in weekly mean concentrations of $\mathrm{SO}_{2}$ over lagged 7, 14 and 21 days in single-pollutant models among all TB patients and subgroups stratified by age and sex.

eFigure 8. Lag-specific relative risks in initial outpatient visits for TB per $10 \mu \mathrm{g} / \mathrm{m}^{3}$ increase in weekly mean concentrations of $\mathrm{NO}_{2}$ over lagged 7, 14 and 21 days in 
single-pollutant models among all TB patients and subgroups stratified by age and sex.

eFigure 9. Lag-specific relative risks in initial outpatient visits for TB per $0.1 \mathrm{mg} / \mathrm{m}^{3}$ increase in weekly mean concentrations of CO over over lagged 7, 14 and 21 days in single-pollutant models among all TB patients and subgroups stratified by age and sex.

\section{Section 6. Sensitivity Analysis}

\section{(1) Sensitivity analysis fitting two-pollutant models}

eFigure 10. Lag-specific relative risks (95\% confidence interval) in initial outpatient visits for TB per $10 \mu \mathrm{g} / \mathrm{m} 3$ increase in weekly mean concentrations of $\mathrm{PM}_{10}$ adjusted with $\mathrm{SO}_{2}, \mathrm{NO}_{2}$ or $\mathrm{CO}$ over lagged 16 weeks in two-pollutant models.

eFigure 11. Lag-specific relative risks (95\% confidence interval) in initial outpatient visits for TB per $10 \mu \mathrm{g} / \mathrm{m} 3$ increase in weekly mean concentrations of $\mathrm{PM}_{2.5}$ adjusted with $\mathrm{SO}_{2}, \mathrm{NO}_{2}$ or $\mathrm{CO}$ over lagged 16 weeks in two-pollutant models.

eFigure 12. Lag-specific relative risks (95\% confidence interval) in initial outpatient visits for TB per $10 \mu \mathrm{g} / \mathrm{m} 3$ increase in weekly mean concentrations of $\mathrm{SO}_{2}$ adjusted with $\mathrm{PM}_{10}, \mathrm{PM}_{2.5}, \mathrm{NO}_{2}$ or $\mathrm{CO}$ over lagged 16 weeks in two-pollutant models.

eFigure 13. Lag-specific relative risks (95\% confidence interval) in initial outpatient visits for TB per $10 \mu \mathrm{g} / \mathrm{m} 3$ increase in weekly mean concentrations of $\mathrm{NO}_{2}$ adjusted with $\mathrm{PM}_{10}, \mathrm{PM}_{2.5}, \mathrm{SO}_{2}$ or $\mathrm{CO}$ over lagged 16 weeks in two-pollutant models.

eFigure 14. Lag-specific relative risks (95\% confidence interval) in initial outpatient visits for TB per $10 \mu \mathrm{g} / \mathrm{m} 3$ increase in weekly mean concentrations of CO adjusted with $\mathrm{PM}_{10}, \mathrm{PM}_{2.5}, \mathrm{SO}_{2}$ or $\mathrm{NO}_{2}$ over lagged 16 weeks in two-pollutant models.

\section{(2) Sensitivity analysis excluding retreated TB cases}

eFigure 15. Lag-specific excess risks(\%) (A) and cumulative excess risks(\%) (B) in total initial outpatient visits for TB when excluding retreated TB cases per 10 units increase in weekly mean concentrations of air pollution over lagged 16 weeks in single-pollutant models.

eFigure 16. Lag-specific excess risks(\%) (A) and cumulative excess risks(\%) (B) in initial outpatient visits for TB when excluding retreated TB cases per 10 units increase 
in the weekly concentrations of air pollution over lagged 16 weeks in single-pollutant models stratified by age.

eFigure 17. Lag-specific excess risks(\%) (A) and cumulative excess risks(\%) (B) in initial outpatient visits for TB when excluding retreated TB cases per 10 units increase in weekly mean concentrations of air pollution over lagged 16 weeks in single-pollutant models stratified by sex.

\section{(3) Sensitivity analysis changing maximum lag and df in DLNM}

eFigure 18. Lag-specific relative risk in initial outpatient visits for TB per 10 units increase in weekly mean concentrations of air pollution over the maximum lags of 12 weeks, 16 weeks and 24 weeks in single-pollutant models.

eFigure 19. Lag-specific relative risk in initial outpatient visits for TB per 10 units increase in weekly mean concentrations of air pollution over lagged 16 weeks in single-pollutant models with $6 \mathrm{df}$ and $7 \mathrm{df}$ in the natural cubic spline of time (weeks). eFigure 20. Lag-specific relative risk in initial outpatient visits for TB per 10 units increase in weekly mean concentrations of air pollution over lagged 16 weeks in single-pollutant models with $3 \mathrm{df}$ and $4 \mathrm{df}$ in the natural cubic spline of meteorological factors.

\section{References}


Section 1. Monitoring stations and trend plots
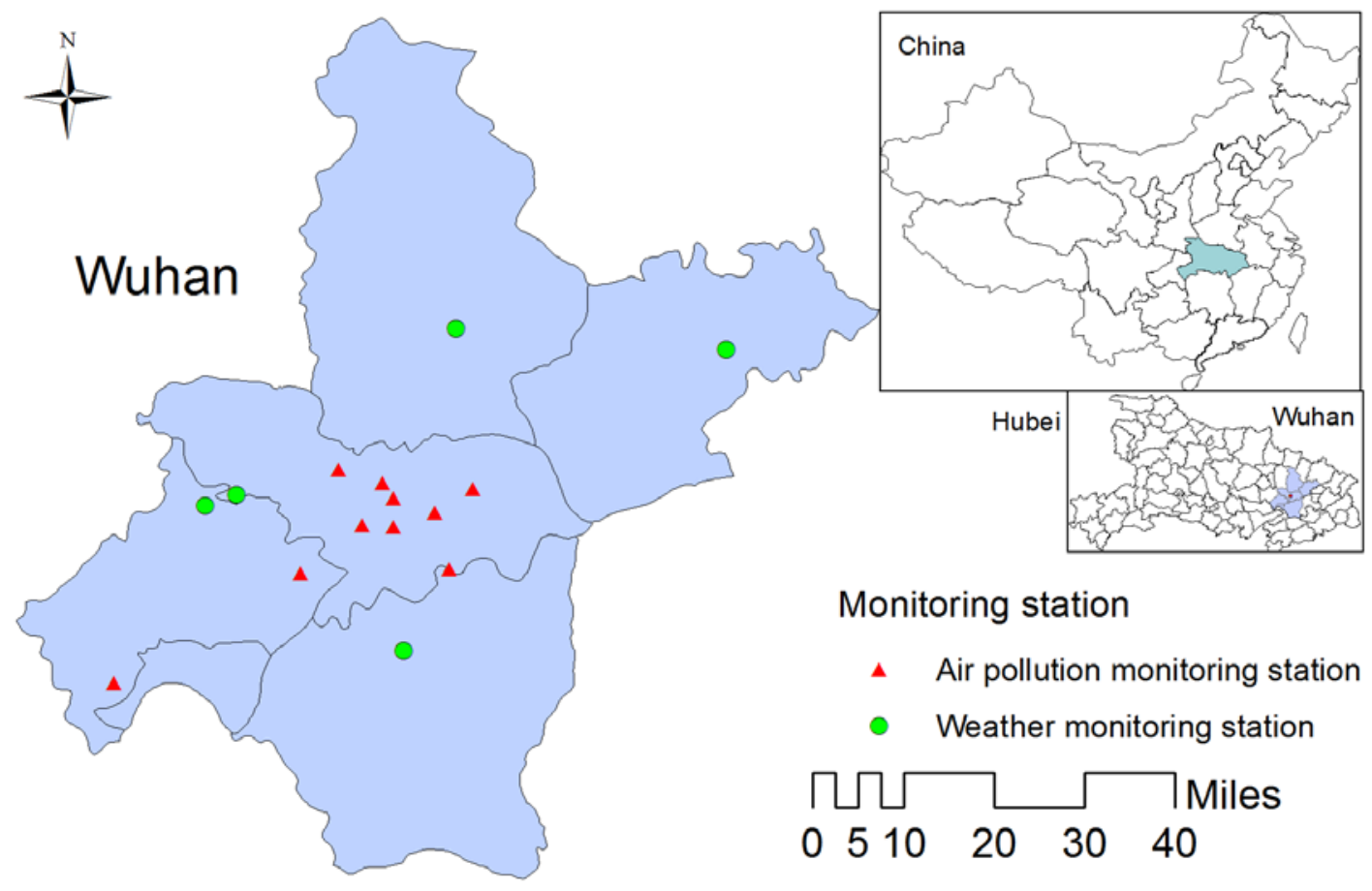

eFigure 1. Wuhan city and the locations of air pollution and weather monitoring stations. 

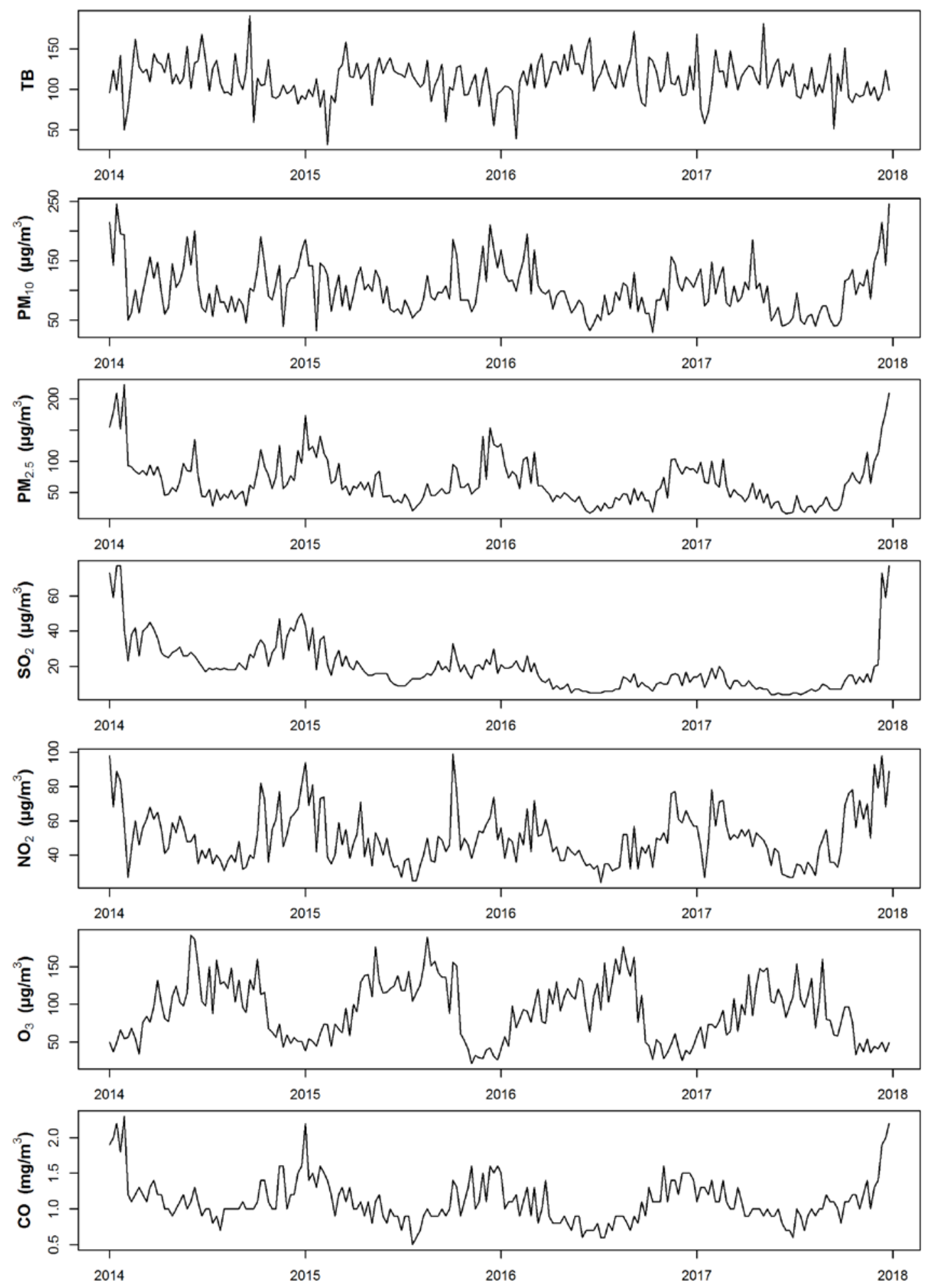

eFigure 2. Trend plot of weekly total TB cases and mean air pollution concentrations in Wuhan during the study period. 

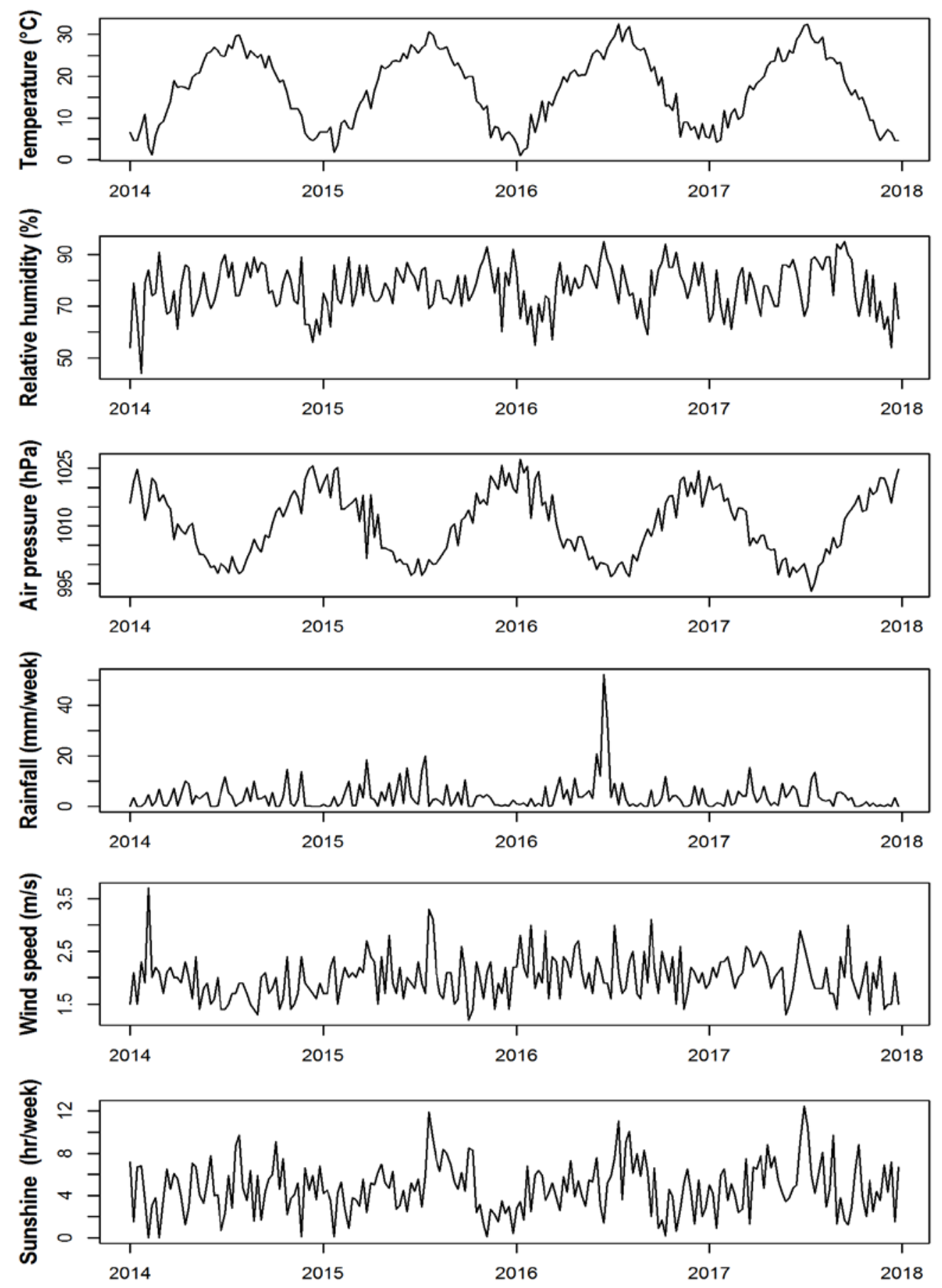

eFigure 3. Trend plot of weekly mean climate measures in Wuhan during the study period. 


\section{Section 2. Distributed lag nonlinear model (DLNM)}

We fitted a DLNM model to assess non-linear exposure-response relationship and lag effects of air pollution on the risk of initial TB consults. Suppose that $Y_{t}$, denotes the number of TB cases of the whole city at calendar time ( week ) $t$, and follows a Poisson distribution by $Y_{t} \mid \mu_{t} \sim \operatorname{POI}\left(\mu_{t}\right)$, where $\mu_{t}$ is the expected value of $Y_{t}$. Hence, a log-linear Poisson model which allows for overdispersion to combine a DLNM was applied. The single-pollutant model specifications used for estimating the relationship between pollution and initial TB cases at each single-week lag were as follows:

$$
\begin{aligned}
\log \left(\mu_{t}\right)=\alpha & +\beta A P_{t, l}+\mathrm{ns}(\text { temp }, 3)+\mathrm{ns}(\text { humidity,3) }+\mathrm{ns}(\text { wind }, 3)+\mathrm{ns}(\text { sunshine }, 3) \\
& +\lambda \text { year }+\mathrm{ns}(\text { time }, 6)+\delta \text { Spring-festival } \\
=\alpha & +\beta A P_{t, l}+\mathrm{COVs}
\end{aligned}
$$

where $\alpha$ is the intercept, and $\mathrm{AP}_{t, l}$ is the cross-basis matrix by using a DLNM to each indicator of air pollution (AP). $\beta$ is the coefficient for $A P_{t, l}, l$ is the lag weeks. The rest meteorological factors and time variables in equation (1) are all covariates. $\lambda$ and $\delta$ stand for coefficients of the dummy variables for year and the Spring Festival. The time spline function concerning the week is a natural cubic spline used for controlling for the temporal autocorrelations with 6 degrees of freedom ( $\mathrm{df}$ ), which was determined based on the model fit using Akaike’s information criterion (AIC). ${ }^{1}$ We added the Spring-festival term to control for the holiday effect. In China, people gather, particularly family members and friends (called union) to celebrate Chinese new year, called as Spring Festival , which would always lead to heath care seeking 
delay ${ }^{2}$. Thus, during the Spring Festival the consultation rate is relatively low. ${ }^{2} \mathrm{We}$ fitted natural cubic splines with a priori $3 \mathrm{df}$ to control for meteorological variables. ${ }^{3}$ As strong correlations between temperature and air pressure $(r=-0.94)$ and between relative humidity and rainfall $(r=0.73$ ) were observed in the initial analysis (see eTable 1), air pressure and rainfall were excluded from the final models to avoid collinearity.

To fully capture the overall impact of pollution and consider any potential harvesting effects, a lag of up to 16 weeks was used for pollution models. We chose 16 weeks based on the reported potential delayed periods of air pollution on TB cases lasting 3 to 6 months, ${ }^{4}$ AIC and considerations of easy interpretation with not very long lags from an epidemiological perspective. ${ }^{5}$ Then, we used a double natural cubic spline DLNM in which we fitted the natural cubic spline function to model both the nonlinear pollution effects and the lag effects. We set the medians of each pollutant concentration as reference values to calculate excess risks (\%). We placed spline knots at equally spaced percentiles of pollution concentrations to allow sufficient flexibility at both ends of pollution concentration distribution; similarly, we laid spline knots at equally spaced $\log _{10}$-value scale of lags so that enough lag effects were allowed at shorter lag periods. ${ }^{5}$ In order to build the best combination of the cross-basis function of air pollution and the lag in the two natural cubic splines, the optimal number of knots for each dimension was chosen on the basis of the smallest quasi-AIC(QAIC) ${ }^{16}$ (see eTable 2). 
eTable 1

Spearman's correlation coefficients between weekly air pollution and meteorological variables in Wuhan, 2014-2017.

\begin{tabular}{|c|c|c|c|c|c|c|c|c|c|c|c|}
\hline & $\mathrm{PM}_{2.5}$ & $\mathrm{PM}_{10}$ & $\mathrm{SO}_{2}$ & $\mathrm{NO}_{2}$ & $\mathrm{CO}$ & Temp & Humi & Press & Rain & Wind & Sun \\
\hline $\mathrm{PM}_{2.5}$ & 1 & $0.83^{\mathrm{a}}$ & $0.74^{\mathrm{a}}$ & $0.75^{\mathrm{a}}$ & $0.81^{\mathrm{a}}$ & $-0.7^{\mathrm{a}}$ & $-0.44^{\mathrm{a}}$ & $0.68^{\mathrm{a}}$ & $-0.46^{\mathrm{a}}$ & $-0.21^{b}$ & -0.12 \\
\hline $\mathrm{PM}_{10}$ & & 1 & $0.63^{\mathrm{a}}$ & $0.79^{\mathrm{a}}$ & $0.58^{\mathrm{a}}$ & $-0.43^{a}$ & $-0.65^{a}$ & $0.46^{\mathrm{a}}$ & $-0.58^{a}$ & $-0.28^{a}$ & $0.24^{b}$ \\
\hline $\mathrm{SO}_{2}$ & & & 1 & $0.57^{\mathrm{a}}$ & $0.57^{\mathrm{a}}$ & $-0.48^{a}$ & $-0.43^{\mathrm{a}}$ & $0.49^{\mathrm{a}}$ & $-0.35^{a}$ & $-0.25^{a}$ & -0.02 \\
\hline $\mathrm{NO}_{2}$ & & & & 1 & $0.68^{\mathrm{a}}$ & $-0.6^{a}$ & $-0.47^{a}$ & $0.6^{\mathrm{a}}$ & $-0.47^{\mathrm{a}}$ & $-0.38^{\mathrm{a}}$ & 0.06 \\
\hline $\mathrm{CO}$ & & & & & 1 & $-0.69^{a}$ & -0.1 & $0.62^{\mathrm{a}}$ & $-0.25^{a}$ & -0.19 & $-0.32^{a}$ \\
\hline Temperature & & & & & & 1 & $0.22^{b}$ & $-0.94^{a}$ & $0.24^{\mathrm{b}}$ & -0.07 & $0.4^{\mathrm{a}}$ \\
\hline Humidity & & & & & & & 1 & $-0.31^{\mathrm{a}}$ & $0.73^{\mathrm{a}}$ & 0.01 & $-0.61^{a}$ \\
\hline Pressure & & & & & & & & 1 & $-0.38^{a}$ & 0.01 & $-0.27^{\mathrm{a}}$ \\
\hline Rainfall & & & & & & & & & 1 & $0.27^{\mathrm{a}}$ & $-0.45^{\mathrm{a}}$ \\
\hline Wind & & & & & & & & & & 1 & -0.07 \\
\hline Sunshine & & & & & & & & & & & 1 \\
\hline
\end{tabular}

$\mathrm{PM}_{10}$ : particulate matter $<10 \mu \mathrm{m}$ in aerodynamic diameter; $\mathrm{PM}_{2.5}$ : particulate matter $<2.5 \mu \mathrm{m}$ in aerodynamic diameter; $\mathrm{NO}_{2}$ : nitrogen dioxide; $\mathrm{CO}$ : carbonic oxide.

${ }^{\text {a }} \mathrm{P}<0.001$

${ }^{\mathrm{b}} \mathrm{P}<0.05$. 
eTable 2

Knots in the double natural cubic splines for the best model fitting in the distributed lag nonlinear model for each pollution model.

\begin{tabular}{lcccc}
\hline Model & Air Pollution & Lag (weeks) & Knots for the predictors & Knots for the lags \\
\hline Model 1 & PM10 $_{10}$ & 16 & 2 & 3 \\
Model 2 & $\mathrm{PM}_{2.5}$ & 16 & 2 & 3 \\
Model 3 & $\mathrm{NO}_{2}$ & 16 & 3 & 2 \\
Model 4 & $\mathrm{CO}$ & 16 & 2 & 3 \\
\hline
\end{tabular}




\section{Section 3. Single-pollutant models in total population and subgroups}

\section{eTable 3}

Lag-specific percentage changes (excess risk with 95\% confidence interval) in initial outpatient visits for TB per $10 \mu \mathrm{g} / \mathrm{m}^{3}$ increase in weekly mean concentrations of $\mathrm{PM}_{10}$ over lagged 16 weeks in single-pollutant models.

\begin{tabular}{|c|c|c|c|c|c|}
\hline Lag (week) & All & 15-59 years old & $\geq 60$ years old & Male & Female \\
\hline 0 & $-0.31(-2.05,1.46)$ & $-0.6(-2.34,1.16)$ & $0.21(-2.39,2.87)$ & $-0.68(-2.5,1.18)$ & $0.6(-1.83,3.1)$ \\
\hline 1 & $-0.47(-1.62,0.7)$ & $-0.61(-1.76,0.56)$ & $-0.03(-1.76,1.72)$ & $-0.83(-2.04,0.39)$ & $0.3(-1.32,1.95)$ \\
\hline 2 & $-0.54(-1.72,0.66)$ & $-0.58(-1.76,0.61)$ & $-0.36(-2.17,1.48)$ & $-0.89(-2.13,0.37)$ & $0.11(-1.59,1.85)$ \\
\hline 3 & $-0.45(-1.62,0.73)$ & $-0.49(-1.66,0.69)$ & $-0.67(-2.26,0.95)$ & $-0.77(-2,0.47)$ & $0.09(-1.41,1.61)$ \\
\hline 4 & $-0.29(-1.31,0.74)$ & $-0.38(-1.4,0.66)$ & $-0.59(-2.32,1.16)$ & $-0.58(-1.65,0.51)$ & $0.15(-1.48,1.79)$ \\
\hline 5 & $-0.14(-1.07,0.8)$ & $-0.27(-1.2,0.67)$ & $-0.26(-1.77,1.27)$ & $-0.4(-1.38,0.59)$ & $0.23(-1.18,1.66)$ \\
\hline 6 & $-0.02(-0.92,0.89)$ & $-0.18(-1.08,0.73)$ & $0.08(-1.23,1.4)$ & $-0.25(-1.19,0.71)$ & $0.31(-0.9,1.54)$ \\
\hline 7 & $0.08(-0.82,0.98)$ & $-0.11(-0.99,0.79)$ & $0.34(-0.89,1.58)$ & $-0.12(-1.06,0.82)$ & $0.37(-0.77,1.52)$ \\
\hline 8 & $0.15(-0.73,1.03)$ & $-0.05(-0.92,0.82)$ & $0.52(-0.67,1.73)$ & $-0.03(-0.94,0.9)$ & $0.41(-0.7,1.52)$ \\
\hline 9 & $0.2(-0.64,1.04)$ & $0(-0.83,0.83)$ & $0.64(-0.5,1.8)$ & $0.05(-0.83,0.93)$ & $0.43(-0.64,1.5)$ \\
\hline 10 & $0.23(-0.55,1.01)$ & $0.03(-0.74,0.81)$ & $0.71(-0.37,1.79)$ & $0.1(-0.71,0.93)$ & $0.43(-0.57,1.44)$ \\
\hline 11 & $0.25(-0.46,0.95)$ & $0.06(-0.64,0.76)$ & $0.72(-0.26,1.7)$ & $0.14(-0.6,0.89)$ & $0.42(-0.48,1.34)$ \\
\hline 12 & $0.25(-0.38,0.88)$ & $0.07(-0.55,0.7)$ & $0.69(-0.17,1.56)$ & $0.17(-0.49,0.83)$ & $0.4(-0.4,1.21)$ \\
\hline 13 & $0.24(-0.33,0.82)$ & $0.08(-0.49,0.66)$ & $0.63(-0.15,1.42)$ & $0.18(-0.42,0.79)$ & $0.38(-0.35,1.11)$ \\
\hline 14 & $0.22(-0.34,0.79)$ & $0.09(-0.48,0.66)$ & $0.55(-0.24,1.33)$ & $0.19(-0.41,0.78)$ & $0.34(-0.38,1.08)$ \\
\hline 15 & $0.2(-0.42,0.83)$ & $0.09(-0.53,0.71)$ & $0.44(-0.45,1.34)$ & $0.18(-0.47,0.84)$ & $0.3(-0.53,1.14)$ \\
\hline 16 & $0.18(-0.55,0.92)$ & $0.09(-0.64,0.83)$ & $0.33(-0.75,1.43)$ & $0.18(-0.59,0.96)$ & $0.26(-0.75,1.29)$ \\
\hline
\end{tabular}




\section{eTable 4}

Lag-specific percentage changes (excess risk with 95\% confidence interval) in initial outpatient visits for TB per $10 \mu \mathrm{g} / \mathrm{m}^{3}$ increase in weekly mean concentrations of $\mathrm{PM}_{2.5}$ over lagged 16 weeks in single-pollutant models.

\begin{tabular}{|c|c|c|c|c|c|}
\hline Lag (week) & All & 15-59 years old & $\geq 60$ years old & Male & Female \\
\hline 0 & $0.71(-1.91,3.41)$ & $-0.62(-2.75,1.56)$ & $1.94(-1.03,5)$ & $-0.47(-2.74,1.86)$ & $2.01(-1.26,5.39)$ \\
\hline 1 & $-0.1(-1.42,1.23)$ & $-0.12(-1.2,0.96)$ & $1.74(0.26,3.25)$ & $0.19(-0.96,1.34)$ & $0.01(-1.62,1.67)$ \\
\hline 2 & $-0.13(-1.71,1.48)$ & $0.17(-0.86,1.21)$ & $1.54(0.12,2.98)$ & $0.57(-0.53,1.68)$ & $-0.42(-2.37,1.56)$ \\
\hline 3 & $0.59(-0.44,1.63)$ & $0.12(-0.94,1.2)$ & $1.32(-0.15,2.81)$ & $0.51(-0.63,1.66)$ & $0.71(-0.57,2.01)$ \\
\hline 4 & $0.77(-0.42,1.98)$ & $-0.09(-0.99,0.81)$ & $1.12(-0.12,2.37)$ & $0.22(-0.74,1.19)$ & $1.17(-0.31,2.68)$ \\
\hline 5 & $0.47(-0.53,1.49)$ & $-0.28(-1.11,0.55)$ & $0.95(-0.18,2.09)$ & $-0.02(-0.9,0.86)$ & $0.91(-0.34,2.17)$ \\
\hline 6 & $0.13(-0.73,1)$ & $-0.41(-1.24,0.44)$ & $0.82(-0.32,1.97)$ & $-0.19(-1.08,0.71)$ & $0.51(-0.55,1.59)$ \\
\hline 7 & $-0.1(-0.97,0.77)$ & $-0.47(-1.34,0.4)$ & $0.72(-0.46,1.92)$ & $-0.28(-1.2,0.66)$ & $0.21(-0.86,1.29)$ \\
\hline 8 & $-0.24(-1.15,0.68)$ & $-0.49(-1.37,0.4)$ & $0.65(-0.55,1.87)$ & $-0.3(-1.24,0.66)$ & $-0.02(-1.13,1.11)$ \\
\hline 9 & $-0.29(-1.22,0.65)$ & $-0.46(-1.34,0.43)$ & $0.61(-0.58,1.82)$ & $-0.26(-1.19,0.69)$ & $-0.17(-1.31,0.99)$ \\
\hline 10 & $-0.27(-1.18,0.66)$ & $-0.39(-1.24,0.47)$ & $0.6(-0.56,1.77)$ & $-0.16(-1.07,0.75)$ & $-0.26(-1.38,0.88)$ \\
\hline 11 & $-0.18(-1.05,0.71)$ & $-0.28(-1.1,0.54)$ & $0.6(-0.52,1.73)$ & $-0.03(-0.9,0.86)$ & $-0.29(-1.37,0.8)$ \\
\hline 12 & $-0.03(-0.87,0.82)$ & $-0.15(-0.96,0.67)$ & $0.62(-0.49,1.74)$ & $0.15(-0.72,1.02)$ & $-0.28(-1.32,0.77)$ \\
\hline 13 & $0.16(-0.7,1.02)$ & $0.01(-0.84,0.87)$ & $0.65(-0.51,1.83)$ & $0.36(-0.55,1.27)$ & $-0.24(-1.3,0.83)$ \\
\hline 14 & $0.38(-0.57,1.33)$ & $0.18(-0.77,1.14)$ & $0.69(-0.6,2.01)$ & $0.59(-0.43,1.61)$ & $-0.17(-1.34,1.02)$ \\
\hline 15 & $0.62(-0.5,1.75)$ & $0.37(-0.74,1.49)$ & $0.74(-0.76,2.27)$ & $0.83(-0.35,2.03)$ & $-0.08(-1.46,1.33)$ \\
\hline 16 & $0.88(-0.48,2.25)$ & $0.56(-0.74,1.88)$ & $0.8(-0.97,2.59)$ & $1.09(-0.3,2.5)$ & $0.02(-1.65,1.72)$ \\
\hline
\end{tabular}

Note: Values were percentage increase (\%) and 95\% CI in risk of outpatient visits for TB.

The bold means statistically significant $(\mathrm{P}<0.05)$. 
eTable 5

Lag-specific percentage changes (excess risk with 95\% confidence interval) in initial outpatient visits for TB per $10 \mu \mathrm{g} / \mathrm{m}^{3}$ increase in weekly mean concentrations of $\mathrm{SO}_{2}$ over lagged 16 weeks in the single-pollutant models.

\begin{tabular}{|c|c|c|c|c|c|}
\hline Lag (week) & All & $15-59$ years old & $\geq 60$ years old & Male & Female \\
\hline 0 & $-1.81(-11.15,8.52)$ & $-1.69(-11.04,8.64)$ & $-15.01(-27.91,0.2)$ & $-4.72(-14.21,5.82)$ & $5.07(-7.55,19.41)$ \\
\hline 1 & $-2.04(-6.38,2.5)$ & $-2.21(-6.55,2.32)$ & $4.09(-2.89,11.58)$ & $-2.85(-7.38,1.89)$ & $-0.3(-5.87,5.6)$ \\
\hline 2 & $-2.22(-5.86,1.56)$ & $-2.6(-6.22,1.15)$ & $8.97(0.24,18.46)$ & $-1.65(-5.51,2.37)$ & $-3.69(-8.2,1.04)$ \\
\hline 3 & $-2.31(-6.18,1.71)$ & $-2.78(-6.61,1.21)$ & $-3.03(-7.93,2.13)$ & $-1.58(-5.68,2.69)$ & $-4.18(-8.97,0.86)$ \\
\hline 4 & $-2.33(-5.36,0.81)$ & $-2.8(-5.81,0.31)$ & $-8.13(-13.46,-2.47)$ & $-2.1(-5.3,1.2)$ & $-3.11(-6.92,0.86)$ \\
\hline 5 & $-2.29(-4.73,0.22)$ & $-2.76(-5.19,-0.26)$ & $-6.61(-10.95,-2.07)$ & $-2.53(-5.1,0.1)$ & $-2.02(-5.14,1.19)$ \\
\hline 6 & $-2.2(-4.47,0.13)$ & $-2.68(-4.94,-0.35)$ & $-3.78(-7.12,-0.33)$ & $-2.76(-5.14,-0.33)$ & $-1.22(-4 \cdot 14,1.78)$ \\
\hline 7 & $-2.07(-4.35,0.27)$ & $-2.56(-4.83,-0.23)$ & $-1.51(-4.65,1.72)$ & $-2.81(-5.19,-0.37)$ & $-0.69(-3.63,2.34)$ \\
\hline 8 & $-1.9(-4.18,0.44)$ & $-2.41(-4.68,-0.08)$ & $0.2(-3.09,3.6)$ & $-2.69(-5.06,-0.25)$ & $-0.4(-3.34,2.64)$ \\
\hline 9 & $-1.69(-3.89,0.55)$ & $-2.22(-4.41,0.02)$ & 1.39(-1.99,4.89) & $-2.42(-4.71,-0.07)$ & $-0.32(-3.15,2.59)$ \\
\hline 10 & $-1.46(-3.48,0.61)$ & $-2.01(-4.03,0.05)$ & $2.11(-1.16,5.49)$ & $-2.02(-4.14,0.15)$ & $-0.44(-3.03,2.23)$ \\
\hline 11 & $-1.2(-3.02,0.66)$ & $-1.78(-3.6,0.07)$ & $2.42(-0.56,5.49)$ & $-1.51(-3.42,0.44)$ & $-0.71(-3.04,1.67)$ \\
\hline 12 & $-0.91(-2.62,0.83)$ & $-1.53(-3.24,0.21)$ & $2.38(-0.28,5.12)$ & $-0.9(-2.71,0.94)$ & $-1.13(-3.29,1.09)$ \\
\hline 13 & $-0.61(-2.46,1.28)$ & $-1.26(-3.11,0.61)$ & $2.07(-0.54,4.75)$ & $-0.21(-2.17,1.78)$ & $-1.64(-3.95,0.72)$ \\
\hline 14 & $-0.29(-2.57,2.05)$ & $-0.98(-3.26,1.34)$ & $1.56(-1.52,4.72)$ & $0.53(-1.89,3.02)$ & $-2.24(-5.06,0.67)$ \\
\hline 15 & $0.04(-2.9,3.06)$ & $-0.7(-3.61,2.31)$ & $0.9(-3.08,5.05)$ & $1.33(-1.81,4.56)$ & $-2.88(-6.48,0.85)$ \\
\hline 16 & $0.37(-3.34,4.22)$ & $-0.4(-4.09,3.42)$ & $0.19(-4.94,5.6)$ & $2.14(-1.83,6.28)$ & $-3.55(-8.04,1.16)$ \\
\hline
\end{tabular}

Note: Values were percentage increase (\%) and 95\% CI in risk of outpatient visits for TB.

The bold means statistically significant $(\mathrm{P}<0.05)$. 


\section{eTable 6}

Lag-specific percentage changes (excess risk with 95\% confidence interval) in initial outpatient visits for TB per $10 \mu \mathrm{g} / \mathrm{m}^{3}$ increase in weekly mean concentrations of $\mathrm{NO}_{2}$ over lagged 16 weeks in single-pollutant models.

\begin{tabular}{|c|c|c|c|c|c|}
\hline Lag (week) & All & 15-59 years old & $\geq 60$ years old & Male & Female \\
\hline 0 & 7.85(0.86,15.32) & $5.88(-1.03,13.27)$ & $12.45(2.59,23.25)$ & $8.39(0.93,16.4)$ & $2.6(-3.22,8.77)$ \\
\hline 1 & $3.61(-0.81,8.22)$ & $2.54(-1.87,7.14)$ & $6.16(0,12.71)$ & $4.07(-0.67,9.03)$ & $0.25(-3.34,3.99)$ \\
\hline 2 & $0.5(-4.03,5.25)$ & $0.02(-4.53,4.78)$ & $1.74(-4.48,8.36)$ & $0.84(-4.02,5.95)$ & $-1.29(-4.86,2.41)$ \\
\hline 3 & $-0.92(-5.18,3.54)$ & $-1.26(-5.55,3.22)$ & $-0.06(-5.89,6.13)$ & $-0.76(-5.33,4.02)$ & $-1.58(-5.09,2.06)$ \\
\hline 4 & $-1.33(-4.68,2.15)$ & $-1.76(-5.13,1.73)$ & $-0.35(-4.95,4.47)$ & $-1.36(-4.95,2.36)$ & $-1.18(-4.24,1.99)$ \\
\hline 5 & $-1.5(-4.27,1.35)$ & $-2.02(-4.8,0.84)$ & $-0.39(-4.2,3.57)$ & $-1.67(-4.63,1.37)$ & $-0.75(-3.62,2.21)$ \\
\hline 6 & $-1.6(-4.18,1.06)$ & $-2.16(-4.76,0.5)$ & $-0.43(-3.99,3.26)$ & $-1.85(-4.6,0.99)$ & $-0.43(-3.31,2.54)$ \\
\hline 7 & $-1.63(-4.22,1.04)$ & $-2.2(-4.8,0.47)$ & $-0.46(-4.03,3.24)$ & $-1.9(-4.66,0.94)$ & $-0.2(-3.14,2.83)$ \\
\hline 8 & $-1.59(-4.22,1.1)$ & $-2.13(-4.76,0.57)$ & $-0.49(-4.11,3.26)$ & $-1.83(-4.63,1.04)$ & $-0.07(-3.02,2.97)$ \\
\hline 9 & $-1.51(-4.11,1.17)$ & $-1.98(-4.59,0.7)$ & $-0.52(-4.1,3.2)$ & $-1.67(-4.45,1.19)$ & $-0.01(-2.89,2.96)$ \\
\hline 10 & $-1.37(-3.9,1.22)$ & $-1.75(-4.29,0.86)$ & $-0.54(-4.02,3.06)$ & $-1.42(-4.12,1.36)$ & $-0.02(-2.78,2.81)$ \\
\hline 11 & $-1.2(-3 \cdot 64,1.3)$ & $-1.46(-3.91,1.06)$ & $-0.56(-3.91,2.9)$ & $-1.09(-3.71,1.59)$ & $-0.09(-2.69,2.58)$ \\
\hline 12 & $-0.99(-3.4,1.49)$ & $-1.11(-3.54,1.39)$ & $-0.58(-3.88,2.83)$ & $-0.7(-3.3,1.96)$ & $-0.21(-2.69,2.34)$ \\
\hline 13 & $-0.75(-3.29,1.85)$ & $-0.71(-3.28,1.92)$ & $-0.6(-4.05,2.97)$ & $-0.26(-2.99,2.55)$ & $-0.37(-2.85,2.18)$ \\
\hline 14 & $-0.49(-3.35,2.45)$ & $-0.29(-3.18,2.7)$ & $-0.62(-4.48,3.4)$ & $0.22(-2.86,3.4)$ & $-0.55(-3.22,2.18)$ \\
\hline 15 & $-0.22(-3.58,3.26)$ & $0.17(-3.25,3.7)$ & $-0.64(-5.16,4.1)$ & $0.73(-2.9,4.5)$ & $-0.76(-3.79,2.36)$ \\
\hline 16 & $0.06(-3.94,4.23)$ & $0.63(-3.43,4.87)$ & $-0.66(-6.01,5)$ & $1.26(-3.06,5.77)$ & $-0.98(-4.5,2.68)$ \\
\hline
\end{tabular}

Note: Values were percentage increase (\%) and 95\% CI in risk of outpatient visits for TB.

The bold means statistically significant $(\mathrm{P}<0.05)$. 
eTable 7

Lag-specific percentage changes (excess risk with 95\% confidence interval) in initial outpatient visits for TB per $10 \mu \mathrm{g} / \mathrm{m}^{3}$ increase in weekly mean concentrations of $\mathrm{CO}$ over lagged 16 weeks in single-pollutant models.

\begin{tabular}{|c|c|c|c|c|c|}
\hline Lag (week) & All & $15-59$ years old & $\geq 60$ years old & Male & Female \\
\hline 0 & $-0.8(-3.07,1.53)$ & $-1.19(-3.48,1.16)$ & $3.46(-2.82,10.14)$ & $-1.09(-3.32,1.19)$ & $-0.2(-3.07,2.75)$ \\
\hline 1 & $0.57(-0.94,2.1)$ & $0.47(-1.06,2.01)$ & $-0.51(-4.7,3.85)$ & $0.36(-1.04,1.79)$ & $0.9(-1,2.85)$ \\
\hline 2 & $1.27(-0.36,2.93)$ & $1.15(-0.5,2.82)$ & $-0.36(-4.61,4.08)$ & $1.29(-0.18,2.78)$ & $1.34(-0.71,3.44)$ \\
\hline 3 & $1.1(-0.24,2.47)$ & $0.67(-0.69,2.06)$ & $3.75(0.4,7.21)$ & $1.31(-0.12,2.75)$ & $0.99(-0.7,2.7)$ \\
\hline 4 & $0.71(-0.71,2.16)$ & $0.22(-1.22,1.67)$ & $5.2(1.47,9.08)$ & $0.84(-0.33,2.02)$ & $0.58(-1.21,2.39)$ \\
\hline 5 & $0.32(-0.86,1.51)$ & $-0.03(-1.22,1.17)$ & $4.08(0.91,7.35)$ & $0.39(-0.66,1.46)$ & $0.26(-1.23,1.77)$ \\
\hline 6 & $0(-1.03,1.04)$ & $-0.18(-1.22,0.87)$ & $2.63(-0.21,5.55)$ & $0.07(-1,1.15)$ & $0(-1.3,1.33)$ \\
\hline 7 & $-0.23(-1.28,0.83)$ & $-0.28(-1.34,0.79)$ & $1.59(-1.37,4.64)$ & $-0.15(-1.26,0.97)$ & $-0.21(-1.54,1.13)$ \\
\hline 8 & $-0.38(-1.49,0.73)$ & $-0.34(-1.45,0.79)$ & $0.94(-2.24,4.22)$ & $-0.28(-1.41,0.87)$ & $-0.4(-1.79,1.02)$ \\
\hline 9 & $-0.47(-1.59,0.67)$ & $-0.35(-1.48,0.8)$ & $0.62(-2.7,4.06)$ & $-0.32(-1.44,0.82)$ & $-0.55(-1.97,0.9)$ \\
\hline 10 & $-0.49(-1.59,0.64)$ & $-0.33(-1.44,0.8)$ & $0.59(-2.78,4.08)$ & $-0.28(-1.37,0.82)$ & $-0.67(-2.07,0.74)$ \\
\hline 11 & $-0.45(-1.51,0.61)$ & $-0.27(-1.33,0.8)$ & $0.8(-2.55,4.27)$ & $-0.19(-1.23,0.86)$ & $-0.78(-2.11,0.57)$ \\
\hline 12 & $-0.37(-1.37,0.63)$ & $-0.2(-1 \cdot 2,0.81)$ & $1.22(-2.09,4.65)$ & $-0.04(-1.04,0.97)$ & $-0.86(-2.11,0.41)$ \\
\hline 13 & $-0.26(-1.24,0.73)$ & $-0.1(-1.08,0.89)$ & $1.81(-1.54,5.28)$ & $0.15(-0.86,1.18)$ & $-0.93(-2.15,0.31)$ \\
\hline 14 & $-0.12(-1.16,0.93)$ & $0.02(-1.03,1.07)$ & $2.53(-1.01,6.19)$ & $0.37(-0.73,1.49)$ & $-0.98(-2.28,0.33)$ \\
\hline 15 & $0.04(-1.16,1.26)$ & $0.14(-1.07,1.36)$ & $3.34(-0.58,7.41)$ & $0.62(-0.65,1.9)$ & $-1.03(-2.52,0.48)$ \\
\hline 16 & $0.21(-1.23,1.67)$ & $0.27(-1.18,1.74)$ & $4.19(-0.28,8.87)$ & $0.88(-0.61,2.39)$ & $-1.08(-2.85,0.72)$ \\
\hline
\end{tabular}

Note: Values were percentage increase (\%) and 95\% CI in risk of outpatient visits for TB.

The bold means statistically significant $(\mathrm{P}<0.05)$. 
Section 4. Analysis stratified by season

(A) Lag-specific effects of air pollution

Group $\&$ Peak * Trough
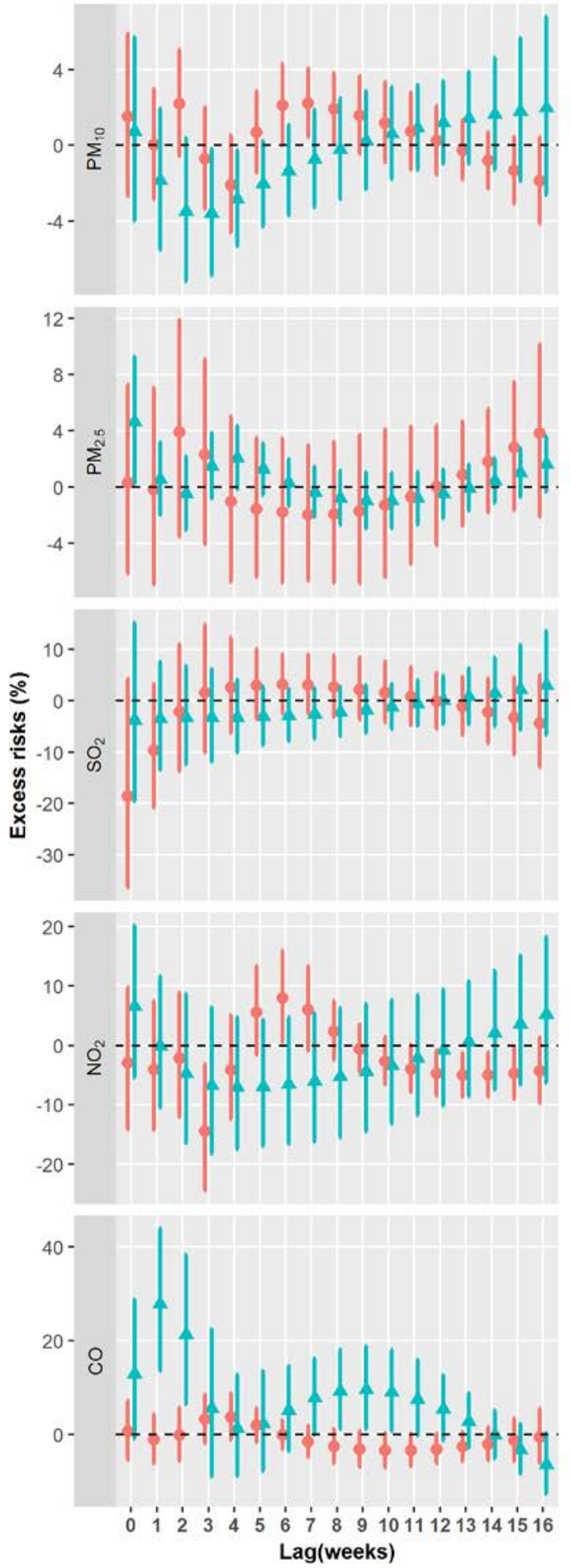

(B) Cumulative effects of air pollution
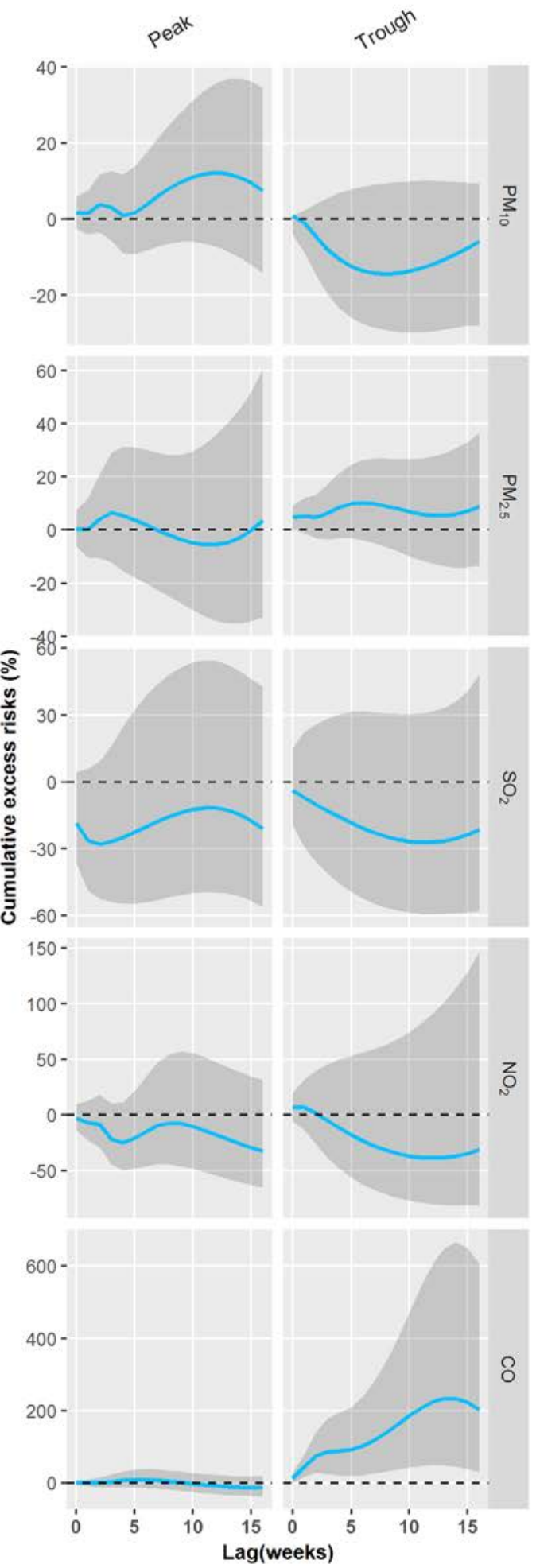

200

eFigure 4. Lag-specific excess risks(\%) (A) and cumulative excess risks(\%) (B) in initial outpatient visits for TB per 10 units increase in weekly mean concentrations of air pollution over lagged 16 weeks in single-pollutant models stratified by the season of TB incidence. 


\section{eTable 8}

Lag-specific percentage changes (excess risk with 95\% confidence interval) in initial outpatient visits for TB per 10 units increase in weekly mean concentrations of air pollutants over lagged 16 weeks in single-pollutant models from March to August.

\begin{tabular}{|c|c|c|c|c|c|}
\hline Lag (week) & $\mathbf{P M}_{10}$ & $\mathbf{P M}_{2.5}$ & $\mathrm{SO}_{2}$ & $\mathrm{NO}_{2}$ & CO \\
\hline 0 & $1.52(-2.69,5.91)$ & $0.34(-6.14,7.27)$ & $-18.58(-36.42,4.26)$ & $-2.94(-14.18,9.78)$ & $0.71(-5.42,7.24)$ \\
\hline 1 & $0.03(-2.84,2.98)$ & $-0.17(-6.93,7.07)$ & $-9.6(-20.9,3.31)$ & $-4.02(-14.24,7.42)$ & $-1.04(-6.1,4.29)$ \\
\hline 2 & $2.2(-0.55,5.03)$ & $3.92(-3.48,11.88)$ & $-2.13(-13.72,11.01)$ & $-2.15(-12.03,8.83)$ & $-0.07(-5.54,5.72)$ \\
\hline 3 & $-0.72(-3.37,2.01)$ & $2.31(-4.05,9.09)$ & $1.56(-10.13,14.77)$ & $-14.44(-24.43,-3.13)$ & $3.26(-1.77,8.54)$ \\
\hline 4 & $-2.09(-4.63,0.52)$ & $-1.02(-6.73,5.03)$ & $2.63(-6.25,12.35)$ & $-4.1(-12.45,5.05)$ & $3.78(-1.01,8.81)$ \\
\hline 5 & $0.67(-1.45,2.84)$ & $-1.55(-6.38,3.52)$ & $3.02(-3.54,10.03)$ & $5.61(-1.64,13.4)$ & $1.97(-1.56,5.63)$ \\
\hline 6 & $2.12(0,4.29)$ & $-1.78(-6.77,3.48)$ & $3.15(-2.45,9.07)$ & $8(0.63,15.9)$ & $-0.02(-3.01,3.06)$ \\
\hline 7 & $2.22(0.43,4.05)$ & $-1.95(-6.63,2.98)$ & $3.04(-2.53,8.94)$ & $5.97(-0.9,13.32)$ & $-1.49(-4.75,1.88)$ \\
\hline 8 & $1.93(0.1,3.81)$ & $-1.93(-6.77,3.18)$ & $2.73(-3.06,8.86)$ & $2.39(-2.43,7.44)$ & $-2.49(-6.09,1.24)$ \\
\hline 9 & $1.58(-0.45,3.65)$ & $-1.69(-6.8,3.69)$ & $2.22(-3.65,8.46)$ & $-0.57(-4.5,3.52)$ & $-3.1(-6.83,0.77)$ \\
\hline 10 & $1.17(-0.92,3.32)$ & $-1.27(-6.36,4.09)$ & $1.56(-4.19,7.66)$ & $-2.63(-6.53,1.42)$ & $-3.36(-6.99,0.4)$ \\
\hline 11 & $0.73(-1.28,2.77)$ & $-0.68(-5.42,4.29)$ & $0.76(-4.75,6.59)$ & $-3.97(-7.89,0.11)$ & $-3.34(-6.71,0.16)$ \\
\hline 12 & $0.24(-1.55,2.07)$ & $0.04(-4.12,4.39)$ & $-0.14(-5.49,5.51)$ & $-4.72(-8.51,-0.78)$ & $-3.06(-6.18,0.16)$ \\
\hline 13 & $-0.27(-1.83,1.32)$ & $0.88(-2.75,4.65)$ & $-1.13(-6.65,4.72)$ & $-5.02(-8.64,-1.25)$ & $-2.59(-5.7,0.62)$ \\
\hline 14 & $-0.8(-2.3,0.72)$ & $1.81(-1.81,5.57)$ & $-2.18(-8.34,4.4)$ & $-4.98(-8.7,-1.1)$ & $-1.98(-5.53,1.71)$ \\
\hline 15 & $-1.35(-3.09,0.43)$ & $2.81(-1.65,7.47)$ & $-3.25(-10.49,4.57)$ & $-4.71(-9.04,-0.17)$ & $-1.25(-5.69,3.39)$ \\
\hline 16 & $-1.89(-4.14,0.4)$ & $3.84(-2.09,10.13)$ & $-4.34(-12.93,5.09)$ & $-4.32(-9.73,1.41)$ & $-0.48(-6.09,5.47)$ \\
\hline
\end{tabular}

Note: Values were percentage increase (\%) and 95\% CI in risk of outpatient visits for TB.

The bold means statistically significant $(\mathrm{P}<0.05)$. 


\section{eTable 9}

Lag-specific percentage changes (excess risk with 95\% confidence interval) in initial outpatient visits for TB per 10 units increase in weekly mean concentrations of air pollutants over lagged 16 weeks in single-pollutant models from September to February in next year.

\begin{tabular}{|c|c|c|c|c|c|}
\hline Lag (week) & $\mathbf{P M}_{10}$ & $\mathbf{P M}_{2.5}$ & $\mathrm{SO}_{2}$ & $\mathrm{NO}_{2}$ & CO \\
\hline 0 & $0.74(-4,5.71)$ & $4.64(0.22,9.26)$ & $-3.73(-19.56,15.21)$ & $6.6(-5.43,20.15)$ & 13.02(-0.87,28.86) \\
\hline 1 & $-1.86(-5.52,1.94)$ & $0.56(-2.01,3.2)$ & $-3.47(-13.46,7.68)$ & $-0.04(-10.48,11.61)$ & 27.89(13.65,43.91) \\
\hline 2 & $-3.49(-7.22,0.39)$ & $-0.47(-3.05,2.18)$ & $-3.28(-12.43,6.82)$ & $-4.74(-16.48,8.65)$ & 21.4(6.49,38.39) \\
\hline 3 & $-3.6(-6.86,-0.22)$ & $1.49(-0.79,3.82)$ & $-3.23(-11.83,6.21)$ & $-6.71(-18.19,6.37)$ & $5.66(-8.81,22.42)$ \\
\hline 4 & $-2.85(-5.34,-0.3)$ & $2.08(-0.14,4.35)$ & $-3.21(-10.02,4.12)$ & $-7.04(-17.47,4.72)$ & $1.42(-8.79,12.78)$ \\
\hline 5 & $-2.05(-4.27,0.22)$ & $1.27(-0.54,3.12)$ & $-3.1(-8.62,2.76)$ & $-6.9(-16.9,4.31)$ & 2.33(-7.73,13.49) \\
\hline 6 & $-1.35(-3.7,1.06)$ & $0.31(-1.34,1.99)$ & $-2.89(-7.84,2.33)$ & $-6.54(-16.57,4.69)$ & $5.23(-3.4,14.63)$ \\
\hline 7 & $-0.74(-3.28,1.87)$ & $-0.36(-2.11,1.43)$ & $-2.58(-7.35,2.43)$ & $-5.99(-16.16,5.41)$ & $7.87(0.07,16.28)$ \\
\hline 8 & $-0.22(-2.84,2.48)$ & $-0.78(-2.67,1.15)$ & $-2.19(-6.86,2.72)$ & $-5.25(-15.48,6.22)$ & $9.33(1.25,18.05)$ \\
\hline 9 & $0.23(-2.34,2.86)$ & $-0.97(-2.93,1.03)$ & $-1.72(-6.26,3.05)$ & $-4.35(-14.49,6.99)$ & $9.68(1.26,18.8)$ \\
\hline 10 & $0.6(-1.81,3.07)$ & $-0.97(-2.92,1.02)$ & $-1.17(-5.56,3.41)$ & $-3.3(-13 \cdot 2,7.74)$ & $9.04(0.71,18.06)$ \\
\hline 11 & $0.92(-1.31,3.2)$ & $-0.79(-2.66,1.1)$ & $-0.57(-4.91,3.96)$ & $-2.11(-11.69,8.52)$ & $7.58(-0.15,15.89)$ \\
\hline 12 & $1.19(-0.98,3.41)$ & $-0.48(-2.22,1.28)$ & $0.08(-4.53,4.9)$ & $-0.8(-10.1,9.47)$ & $5.45(-1.27,12.63)$ \\
\hline 13 & $1.42(-0.98,3.88)$ & $-0.06(-1.68,1.59)$ & $0.77(-4.55,6.39)$ & $0.61(-8.62,10.77)$ & $2.84(-2.8,8.81)$ \\
\hline 14 & $1.62(-1.31,4.64)$ & $0.45(-1.14,2.07)$ & $1.5(-4.97,8.42)$ & $2.1(-7.43,12.61)$ & $-0.09(-5.05,5.12)$ \\
\hline 15 & $1.8(-1.9,5.64)$ & $1.02(-0.68,2.75)$ & $2.26(-5.69,10.87)$ & $3.66(-6.65,15.11)$ & $-3.19(-8.36,2.27)$ \\
\hline 16 & $1.97(-2.62,6.78)$ & $1.63(-0.33,3.62)$ & $3.03(-6.58,13.63)$ & $5.27(-6.3,18.26)$ & $-6.31(-12.53,0.35)$ \\
\hline
\end{tabular}

Note: Values were percentage increase (\%) and 95\% CI in risk of outpatient visits for TB.

The bold means statistically significant $(\mathrm{P}<0.05)$. 


\section{Section 5. Analysis at daily level}

\section{(1) Distributed lag nonlinear model (DLNM) at daily level}

Here we developed a DLNM to assess non-linear exposure-response dependencies and lag effects of air pollution on TB cases at daily level. Suppose that $\mathrm{Y}_{\mathrm{t}}$, denotes the number of daily TB cases of the whole city, and follows a Poisson distribution by $\mathrm{Y}_{\mathrm{t}} \mid \mu_{\mathrm{t}} \sim \operatorname{POI}\left(\mu_{\mathrm{t}}\right)$, where $\mu_{\mathrm{t}}$ is the expected value of $\mathrm{Y}_{\mathrm{t}}$. Hence, we used a generalized additive regression with a log-linear Poisson model that allowed for overdispersion to combine a DLNM. The single-pollutant model specifications used for estimating the relationship between air pollution and initial TB cases at various single-day lags were as follows:

$$
\begin{aligned}
\log \left(\mu_{\mathrm{t}}\right)= & \alpha+\beta \mathrm{AP}_{t, l}+\mathrm{ns}(\text { temp,3) }+\mathrm{ns}(\text { humidity,3) }+\mathrm{ns}(\text { wind,3) }+\mathrm{ns}(\text { sunshine,3) } \\
& +\mathrm{ns}(\text { time, } 7 * 4)+\lambda \mathrm{DOW}+\delta \text { Spring-festival } \\
= & \alpha+\beta \mathrm{C}_{t, l}+\mathrm{COVs}
\end{aligned}
$$

where $\alpha$ is the intercept, and $\mathrm{AP}_{t, l}$ is cross-basis matrix obtained by applying a DLNM to each indicator of air pollution. $\beta$ is the coefficient for $\mathrm{AP}_{t, l}, l$ is the max lag days, and $\lambda$ and $\delta$ stand for coefficients of the dummy variable for "day of week (DOW)" and the Spring Festival, which were used to exclude possible variations of initial TB outpatient visits within a week and during the Spring Festival. We used a natural cubic spline of time with 7 degrees of freedom ( $\mathrm{df}$ ) per year to control for the seasonality and the long-term trend of initial TB outpatient visits. We chose 7 degrees of freedom(df) based on model fit using Akaike's information criterion (AIC) ${ }^{1}$. We fitted natural cubic splines with a priori $3 \mathrm{df}$ to control for meteorological variables. In spearman correlation analysis, we noticed a strong negative correlation between temperature and air pressure $(\mathrm{r}=-0.91)$ and a strong positive correlation between relative humidity and rainfall $(\mathrm{r}=0.69$ ) (eTable 10). To avoid collinearity, air pressure and rainfall were excluded in the final models.

We separately developed the single-pollutant models over lagged 7, 14 and 21 days. To fully capture the overall impact of pollution and adjust for any potential 
harvesting, a maximum lag of 21 days was chosen for the pollution model based on the potential delayed periods of effects of air pollution on TB in a previous study ${ }^{7}$ and exploratory analysis, as well as considering difficulty in interpretation with very long lags. Then we used a double natural cubic spline DLNM in which we fitted the natural cubic spline function to model both the nonlinear pollution effects and the lag effects. We set the medians of each pollutant concentration as reference values to calculate excess risks(\%). We placed spline knots at equally spaced percentiles of pollution concentrations to allow sufficient flexibility at both ends of pollution concentration distribution; similarly, we laid spline knots at equally spaced $\log _{10}$-value scale of lags so that enough lag effects were allowed at shorter lag periods. ${ }^{5}$ In order to build the best combination of the cross-basis function of air pollution and the lag in the two natural cubic splines, the optimal number of knots for each dimension was chosen on the basis of the smallest quasi-AIC (QAIC).$^{16}$

We estimated lag-specific excess risks (\%) of air pollution on initial TB outpatient visits with an increase of 10 units in the concentrations of air pollution at various single-day lags (efigures 5-9). For instance, a lag of 0 day (unlagged) corresponds to the associations between air pollution in a given day and the risk of initial TB outpatient visits in that same day. Then we analyzed the relationship between air pollution and initial TB visits stratified by age and sex in the single pollutant model. Children ( $<15$ years old) were excluded from subgroup analyses as the sample of this group was too small. 


\section{eTable 10}

Spearman's correlation coefficients between daily air pollution and meteorological variables in Wuhan,2014-2017.

\begin{tabular}{|c|c|c|c|c|c|c|c|c|c|c|c|}
\hline & $\mathrm{PM}_{2.5}$ & $\mathrm{PM}_{10}$ & $\mathrm{SO}_{2}$ & $\mathrm{NO}_{2}$ & $\mathrm{CO}$ & Temp & Humi & Press & Rain & Wind & Sun \\
\hline $\mathrm{PM}_{2.5}$ & 1 & $0.83^{\mathrm{a}}$ & $0.68^{\mathrm{a}}$ & $0.7^{\mathrm{a}}$ & $0.79^{\mathrm{a}}$ & $-0.52^{\mathrm{a}}$ & $-0.32^{\mathrm{a}}$ & $0.51^{\mathrm{a}}$ & $-0.33^{\mathrm{a}}$ & $-0.29^{a}$ & -0.02 \\
\hline $\mathrm{PM}_{10}$ & & 1 & $0.62^{\mathrm{a}}$ & $0.78^{\mathrm{a}}$ & $0.62^{\mathrm{a}}$ & $-0.26^{\mathrm{a}}$ & $-0.56^{\mathrm{a}}$ & $0.33^{\mathrm{a}}$ & $-0.51^{\mathrm{a}}$ & $-0.33^{\mathrm{a}}$ & $0.27^{\mathrm{a}}$ \\
\hline $\mathrm{SO}_{2}$ & & & 1 & $0.6^{\mathrm{a}}$ & $0.54^{\mathrm{a}}$ & $-0.4^{\mathrm{a}}$ & $-0.48^{\mathrm{a}}$ & $0.44^{\mathrm{a}}$ & $-0.35^{a}$ & $-0.26^{a}$ & $0.11^{\mathrm{a}}$ \\
\hline $\mathrm{NO}_{2}$ & & & & 1 & $0.67^{\mathrm{a}}$ & $-0.38^{a}$ & $-0.41^{\mathrm{a}}$ & $0.41^{\mathrm{a}}$ & $-0.43^{a}$ & $-0.58^{a}$ & $0.19^{\mathrm{a}}$ \\
\hline $\mathrm{CO}$ & & & & & 1 & $-0.46^{\mathrm{a}}$ & -0.05 & $0.4^{\mathrm{a}}$ & $-0.17^{\mathrm{a}}$ & $-0.31^{\mathrm{a}}$ & $-0.13^{a}$ \\
\hline Temperature & & & & & & 1 & $0.13^{\mathrm{a}}$ & $-0.91^{\mathrm{a}}$ & 0.05 & 0.03 & $0.32^{\mathrm{a}}$ \\
\hline Humidity & & & & & & & 1 & $-0.28^{a}$ & $0.69^{\mathrm{a}}$ & 0.03 & $-0.59^{a}$ \\
\hline Pressure & & & & & & & & 1 & $-0.22^{\mathrm{a}}$ & $-0.08^{b}$ & $-0.15^{a}$ \\
\hline Rainfall & & & & & & & & & 1 & $0.28^{\mathrm{a}}$ & $-0.62^{a}$ \\
\hline Wind & & & & & & & & & & 1 & $-0.15^{a}$ \\
\hline Sunshine & & & & & & & & & & & 1 \\
\hline
\end{tabular}

$\mathrm{PM}_{10}$ : particulate matter $<10 \mu \mathrm{m}$ in aerodynamic diameter; $\mathrm{PM}_{2.5}$ : particulate matter $<2.5 \mu \mathrm{m}$ in aerodynamic diameter; $\mathrm{SO}_{2}$ : sulfur dioxide; $\mathrm{NO}_{2}$ : nitrogen dioxide; $\mathrm{CO}$ : carbonic oxide; $\mathrm{O}_{3}$ : ozone.

${ }^{\text {a }} \mathrm{P}<0.001$

${ }^{\mathrm{b}} \mathrm{P}<0.05$ 
(2) Single-pollutant models in total population and subgroups at daily level

$\operatorname{lag}=7$
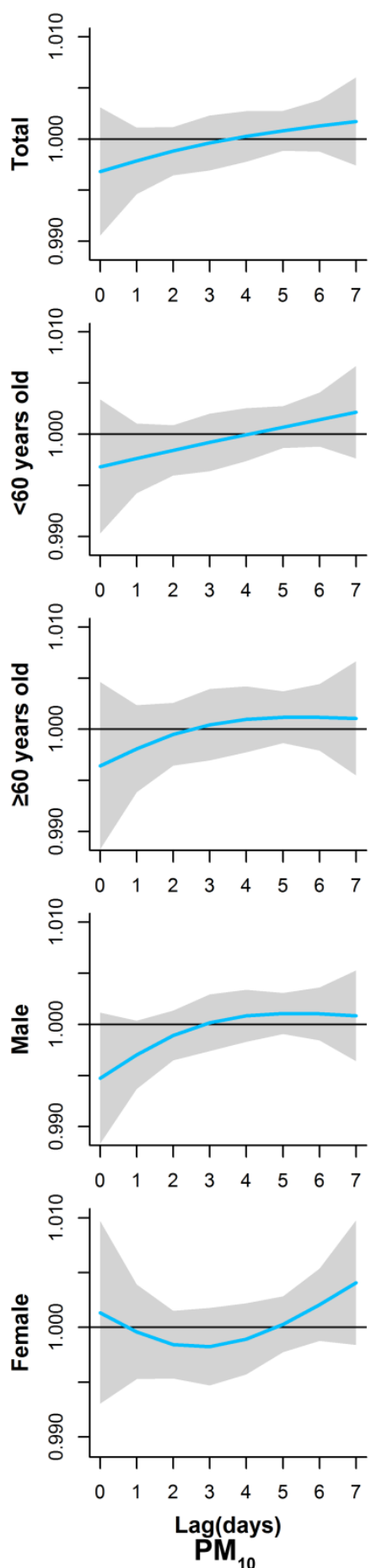

$\operatorname{lag}=14$
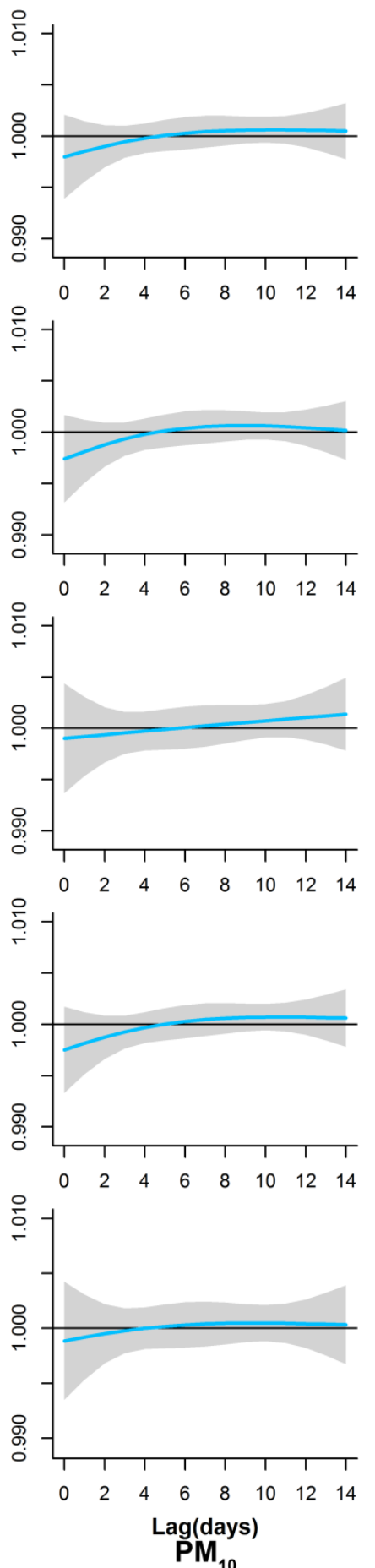

$\operatorname{lag}=\mathbf{2 1}$
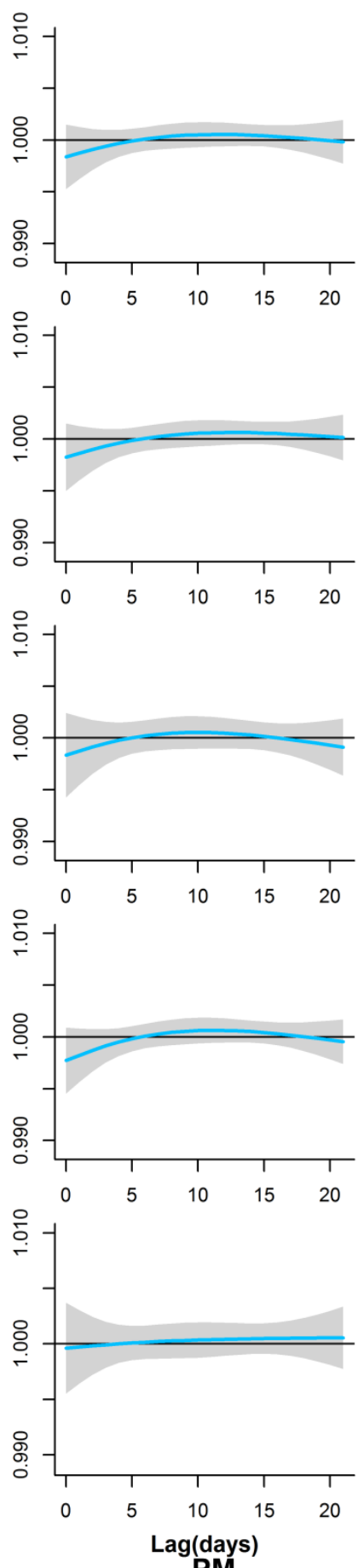

$\mathrm{PM}_{10}$

eFigure 5. Lag-specific relative risks in initial outpatient visits for TB per $10 \mu \mathrm{g} / \mathrm{m}^{3}$ increase in weekly mean concentrations of $\mathrm{PM}_{10}$ over lagged 7, 14 and 21 days in single-pollutant models among all TB patients and subgroups stratified by age and sex. 

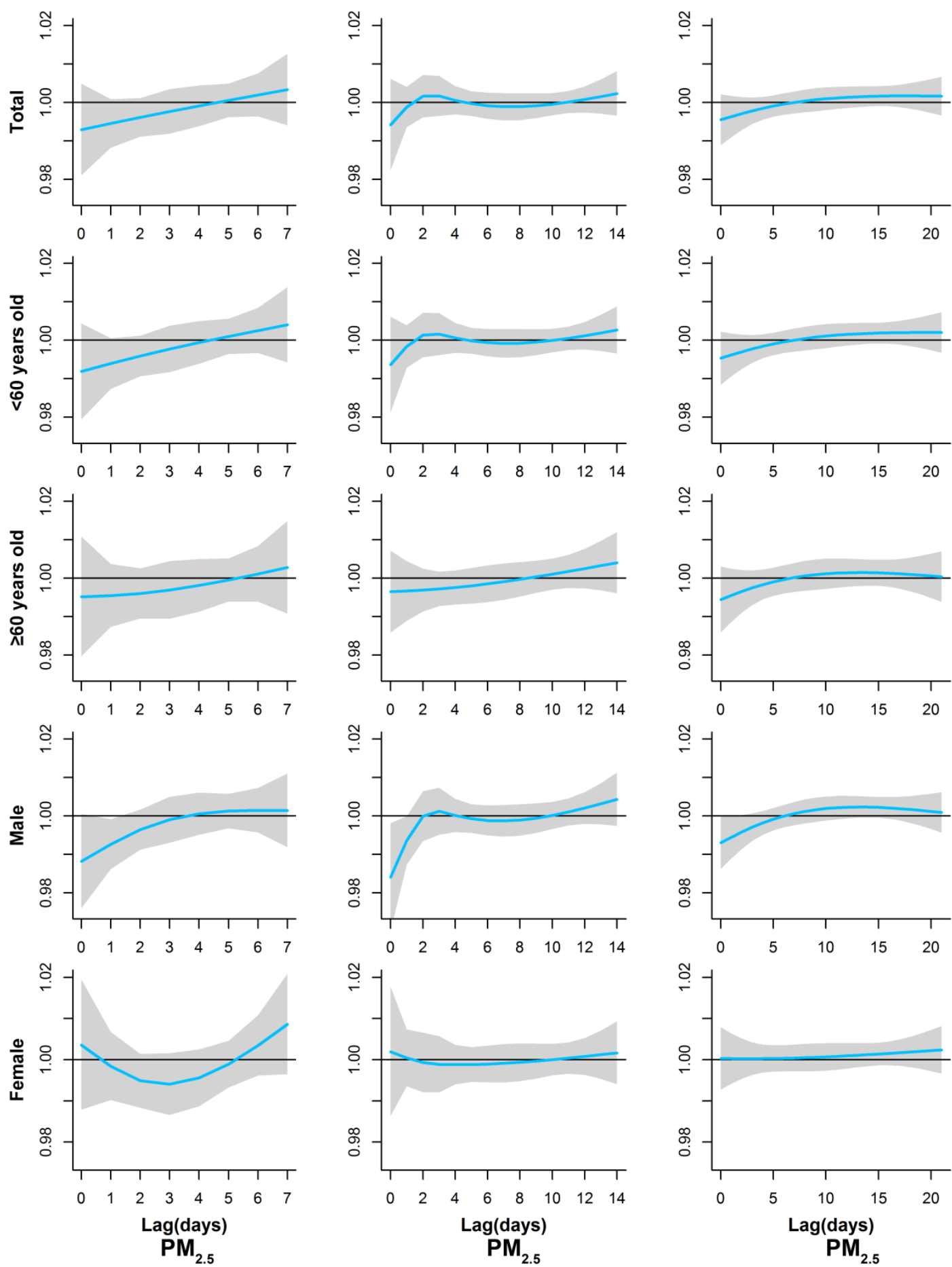

eFigure 6. Lag-specific relative risks in initial outpatient visits for TB per $10 \mu \mathrm{g} / \mathrm{m}^{3}$ increase in weekly mean concentrations of $\mathrm{PM}_{2.5}$ over lagged 7, 14 and 21 days in single-pollutant models among all TB patients and subgroups stratified by age and sex. 

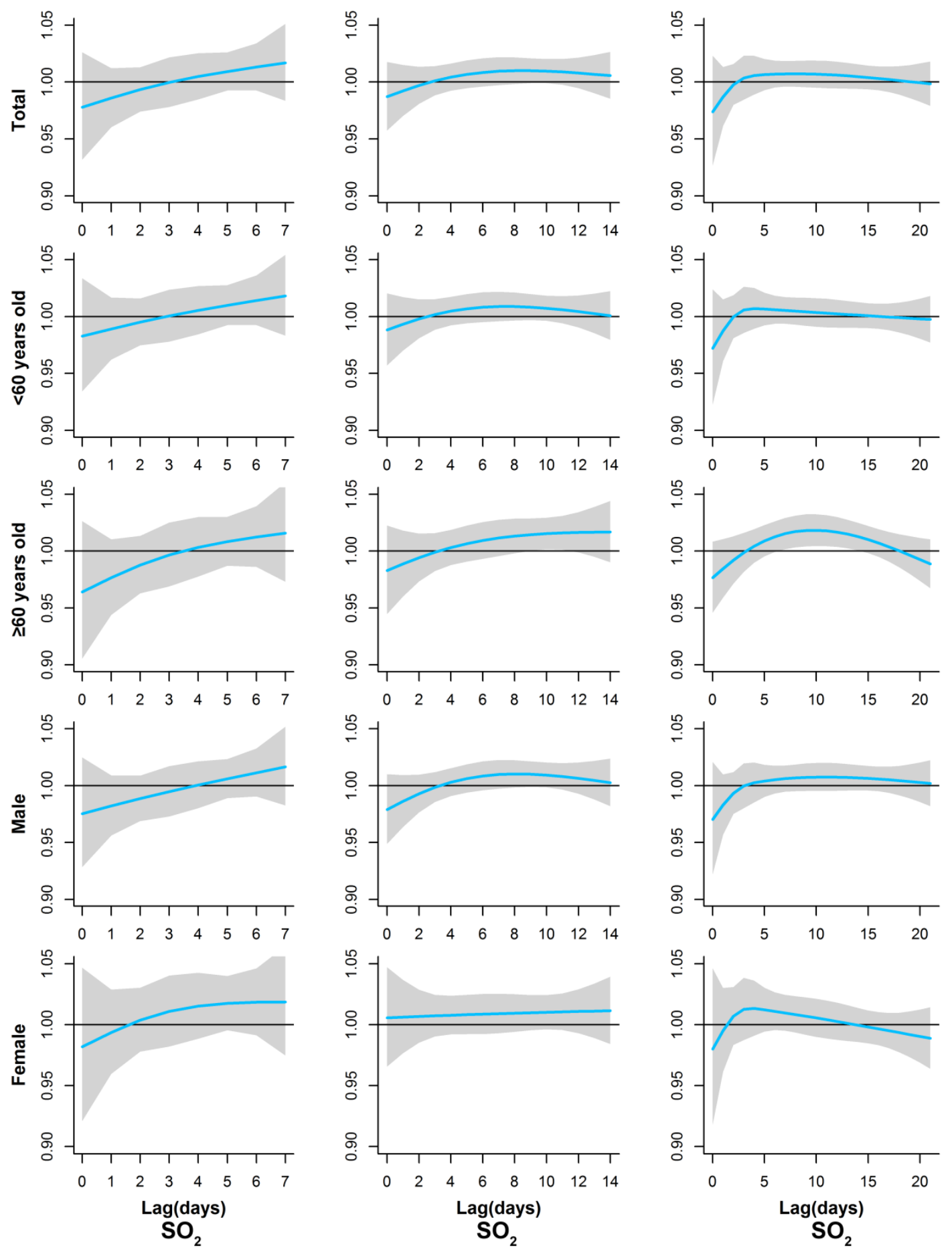

eFigure 7. Lag-specific relative risks in initial outpatient visits for TB per $10 \mu \mathrm{g} / \mathrm{m}^{3}$ increase in weekly mean concentrations of $\mathrm{SO}_{2}$ over lagged 7, 14 and 21 days in single-pollutant models among all TB patients and subgroups stratified by age and sex. 

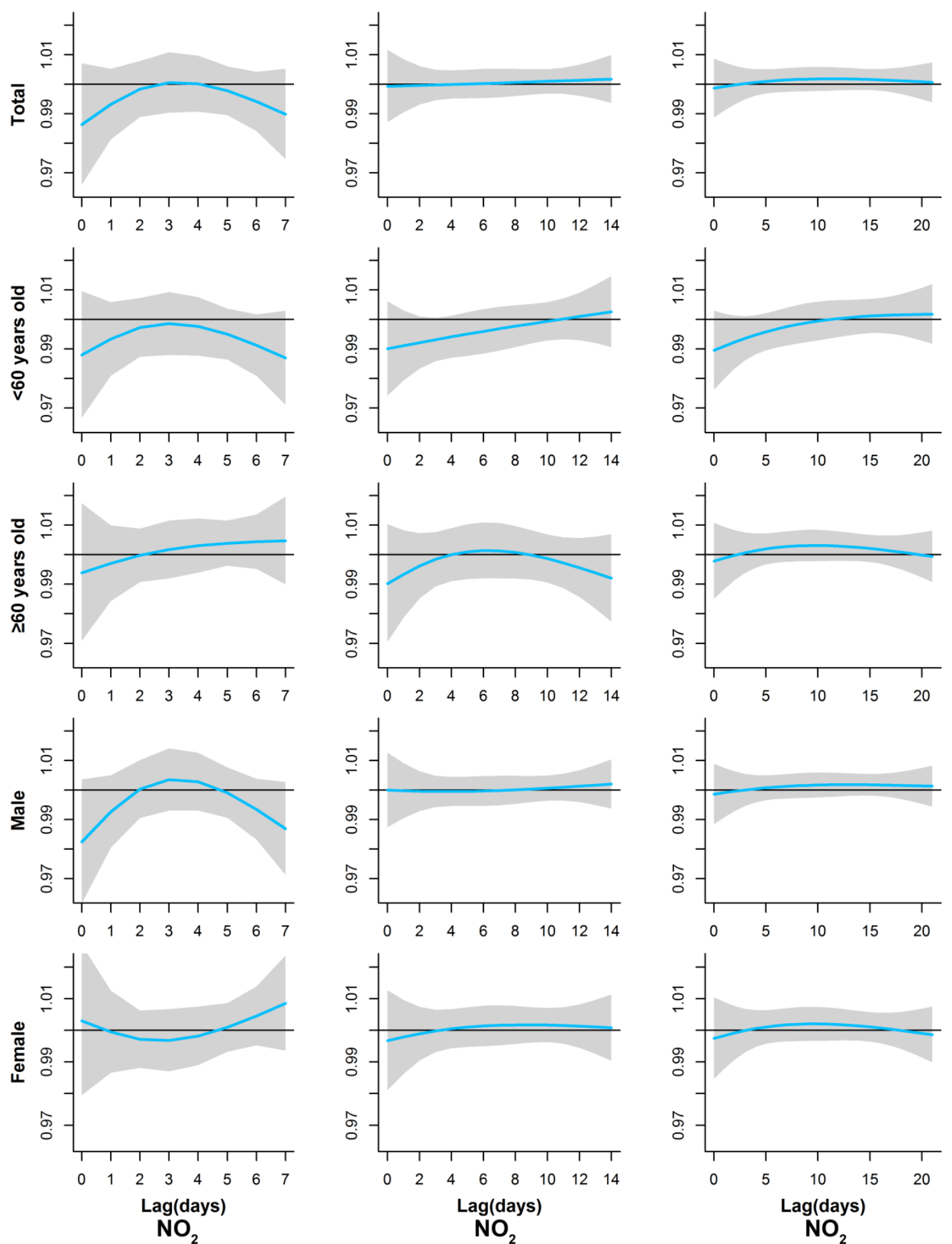

eFigure 8. Lag-specific relative risks in initial outpatient visits for TB per $10 \mu \mathrm{g} / \mathrm{m}^{3}$ increase in weekly mean concentrations of $\mathrm{NO}_{2}$ over lagged 7, 14 and 21 days in single-pollutant models among all TB patients and subgroups stratified by age and sex. 
$\operatorname{lag}=7$
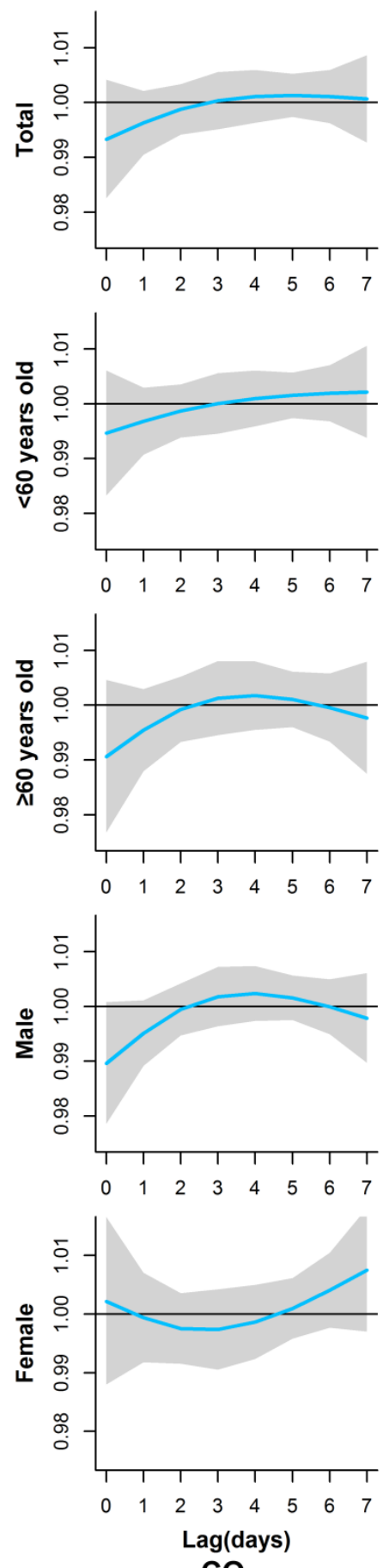

$\operatorname{lag}=14$
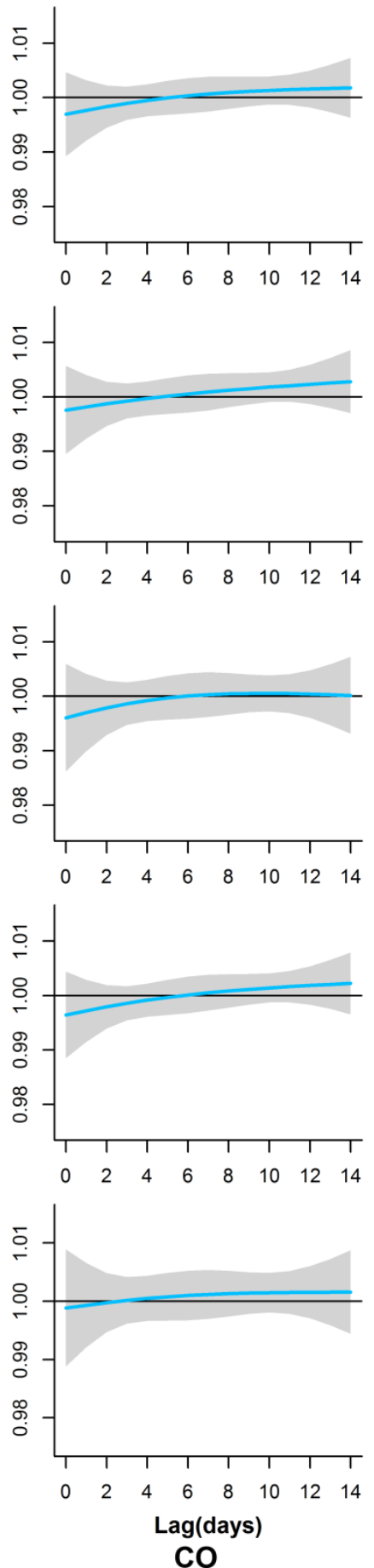

$\operatorname{lag}=\mathbf{2 1}$
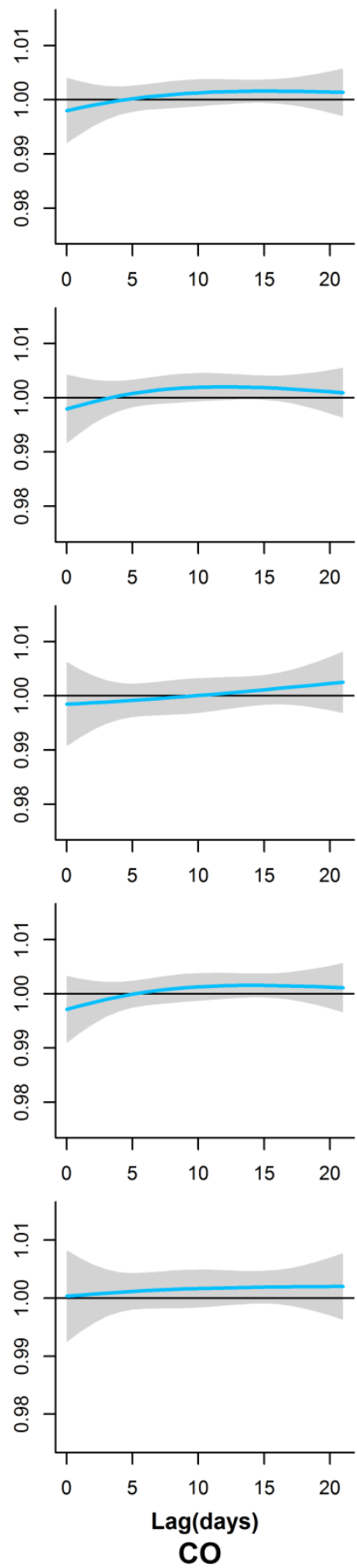

eFigure 9. Lag-specific relative risks in initial outpatient visits for TB per $0.1 \mathrm{mg} / \mathrm{m} 3$ increase in weekly mean concentrations of CO over lagged 7, 14 and 21 days in single-pollutant models among all TB patients and subgroups stratified by age and sex. 


\section{Section 6. Sensitivity Analysis}

Based on the main models, we conducted several sensitivity analyses to assess the robustness of our results. Firstly, to eliminate the potential confounding factors caused by retreatment, we excluded $1,331(5.3 \%)$ retreated TB cases due to failure in the first treatment, recuperation of sputum smear-positive TB after full course of medication, irregular chemotherapy for more than one month or chronic persistent bacteriostasis. Secondly, two-pollutant models were applied to estimate percentage changes in lag-specific excess risks (\%) of each air pollutant in the single-pollutant model among all TB cases and subgroups when stratified by age and sex. Thirdly, as the notified monthly TB case number was previously reported to be associated with the level of air pollution back to 3-6 months ago, ${ }^{3}$ we changed the maximum lags from 16 weeks to 12 and 24 weeks in the final model. We then changed the $\mathrm{df}$ in the natural cubic spline of time from $6 \mathrm{df}$ to $7 \mathrm{df}$ per year to evaluate whether more flexible spline would have a substantial influence on our findings. Similarly, we changed the $\mathrm{df}$ in the natural cubic spline of meteorological factors from $3 \mathrm{df}$ to $4 \mathrm{df}$.

We conducted a series of two-pollutant models (eFigure 10-14). When adjusted with $\mathrm{CO}$, significant lag effects of $\mathrm{PM}_{10}$ at lag 9-13 weeks appeared among female patients, which indicated that $\mathrm{CO}$ might have potential synergistic effects on $\mathrm{PM}_{10}$. When adjusted with $\mathrm{NO}_{2}$, the observed lag effects of $\mathrm{PM}_{2.5}$ at lag 1-2 weeks in the single-pollutant models among old patients extend to lag 2-5 weeks; when adjusted with $\mathrm{CO}$, significant stronger lag effects of $\mathrm{PM}_{2.5}$ were observed at lag 2-16 weeks among old patients. The findings indicated that $\mathrm{CO}$ and $\mathrm{NO}_{2}$ might have potential synergistic effects on $\mathrm{PM}_{2.5}$. When adjusted with $\mathrm{PM}_{10}$ or $\mathrm{PM}_{2.5}$, the lag effect of $\mathrm{SO}_{2}$ 
at lag 0 week among old patients was observed in the two-pollutant models but the positive effects at lag 0 among old patients in the single-pollutant model disappeared; When adjusted with $\mathrm{NO}_{2}$, the lag effects of $\mathrm{SO}_{2}$ at lag 0 week among the total patients and old patients and the additional positive effects at lag 11-13 weeks among old patients were observed in the two-pollutant models; When adjusted with CO, the lag effects of $\mathrm{SO}_{2}$ at lag 5-6 weeks among the total patients and the additional effect at lag 3 week among the female patients were observed in the two-pollutant models, and other significant lag effects of $\mathrm{SO}_{2}$ became stronger in two-pollutant models. When adjusted with $\mathrm{PM}_{10}$, the observed lag effects of $\mathrm{NO}_{2}$ at lag 0 week in the single-pollutant model among all TB patients, old patients and male ones became stronger but the lag effects of $\mathrm{NO}_{2}$ at lag 2 week in the single-pollutant models among old patients was not significant; when adjusted with $\mathrm{PM}_{2.5}$, the observed effects of $\mathrm{NO}_{2}$ in the single-pollutant models were only significant among the male patients but not among all TB patients or old patients; when adjusted with $\mathrm{SO}_{2}$, the observed effects of $\mathrm{NO}_{2}$ at lag 0 - 1 weeks in the single-pollutant models were only significant among the old patients were only significant at lag 0 week ; when adjusted with CO, significant lag effects of $\mathrm{NO}_{2}$ were observed at lag 0-1 weeks, lag 0 week and lag 0-1 weeks among all TB patients, old patients and male ones, respectively. The results indicated that $\mathrm{PM}_{10}$ and $\mathrm{CO}$ might have potential synergistic effects on $\mathrm{NO}_{2}$ but $\mathrm{PM}_{2.5}$ might have potential antagonistic effects on $\mathrm{NO}_{2}$. When adjusted with $\mathrm{PM}_{10}$, the lag effects of CO were observed at lag week 4 and lag week 16; when adjusted with PM 2.5, the lag effects of $\mathrm{CO}$ were observed at lag 4-5 weeks; when adjusted with $\mathrm{NO}_{2}$, the 
lag effects of CO were observed at lag 4-5 weeks and lag 15-16 weeks; when adjusted with $\mathrm{SO}_{2}$, the lag effects of $\mathrm{CO}$ were only observed at lag 3 . The results indicated that $\mathrm{NO}_{2}$ might have potential synergistic effects on $\mathrm{CO}$ and $\mathrm{SO}_{2}$ might have potential antagonistic effects on CO. Overall, the two-pollutant models indicated potential interactions between some pollutants.

Then, when we excluded retreated TB cases, the main results among all TB patients and subgroups were not greatly changed(eFigure 15-17). Finally, we changed the max lag period and the dfs of time and meteorological factors in the spline functions in the DLNM. When changing the max lags, patterns of associations between air pollutants and initial TB consults were generally similar to our main findings except the models of $\mathrm{PM}_{2.5}$ (eFigure 18); when changing from $6 \mathrm{df}$ to $7 \mathrm{df}$ in the spline on the smoother time and changing from $3 \mathrm{df}$ to $4 \mathrm{df}$ in the spline on meteorological factors, the findings were generally similar to our main results (eFigure 19-20 ). 
(1) Sensitivity analysis fitting two-pollutant models

Adjusted $\mathrm{SO}_{2}$
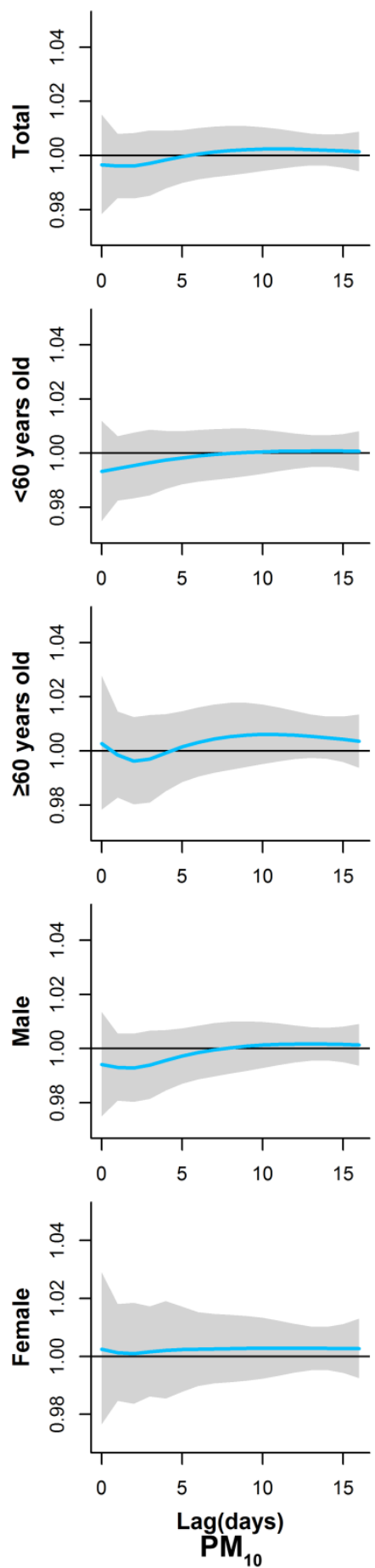

Adjusted $\mathrm{NO}_{2}$
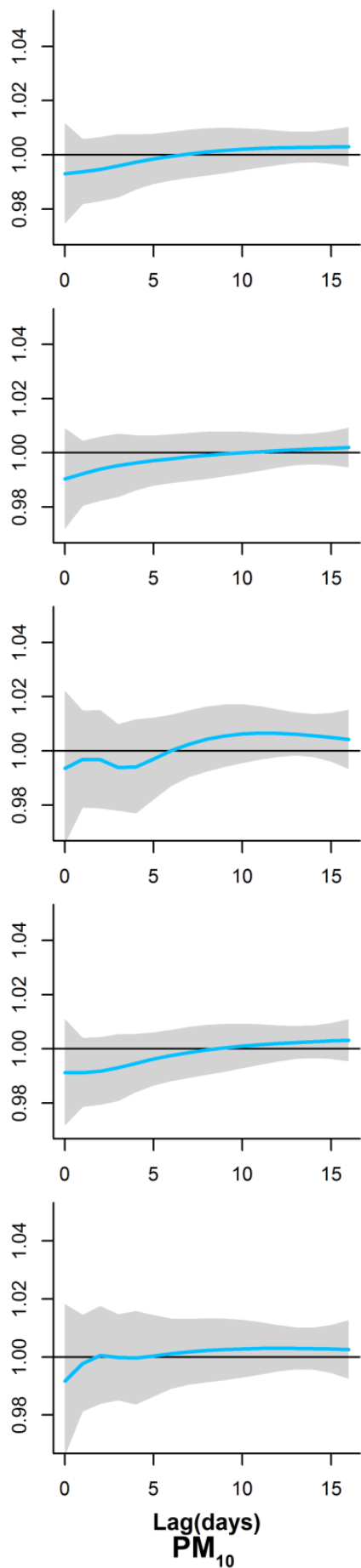

Adjusted $\mathrm{CO}$
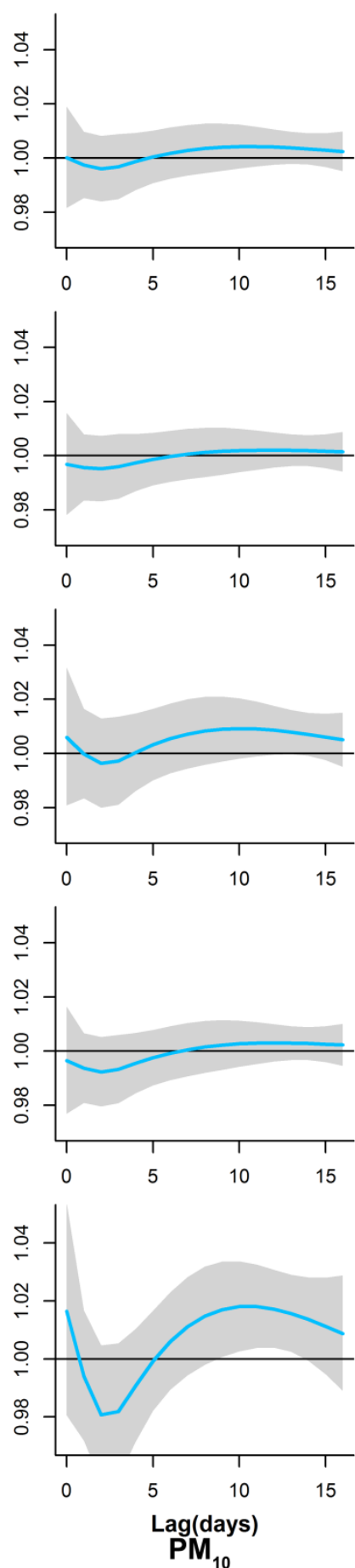

eFigure 10. Lag-specific relative risks (95\% confidence interval) in initial outpatient visits for TB per $10 \mu \mathrm{g} / \mathrm{m} 3$ increase in weekly mean concentrations of $\mathrm{PM}_{10}$ adjusted with $\mathrm{SO}_{2}, \mathrm{NO}_{2}$ or $\mathrm{CO}$ over lagged 16 weeks in two-pollutant models. 

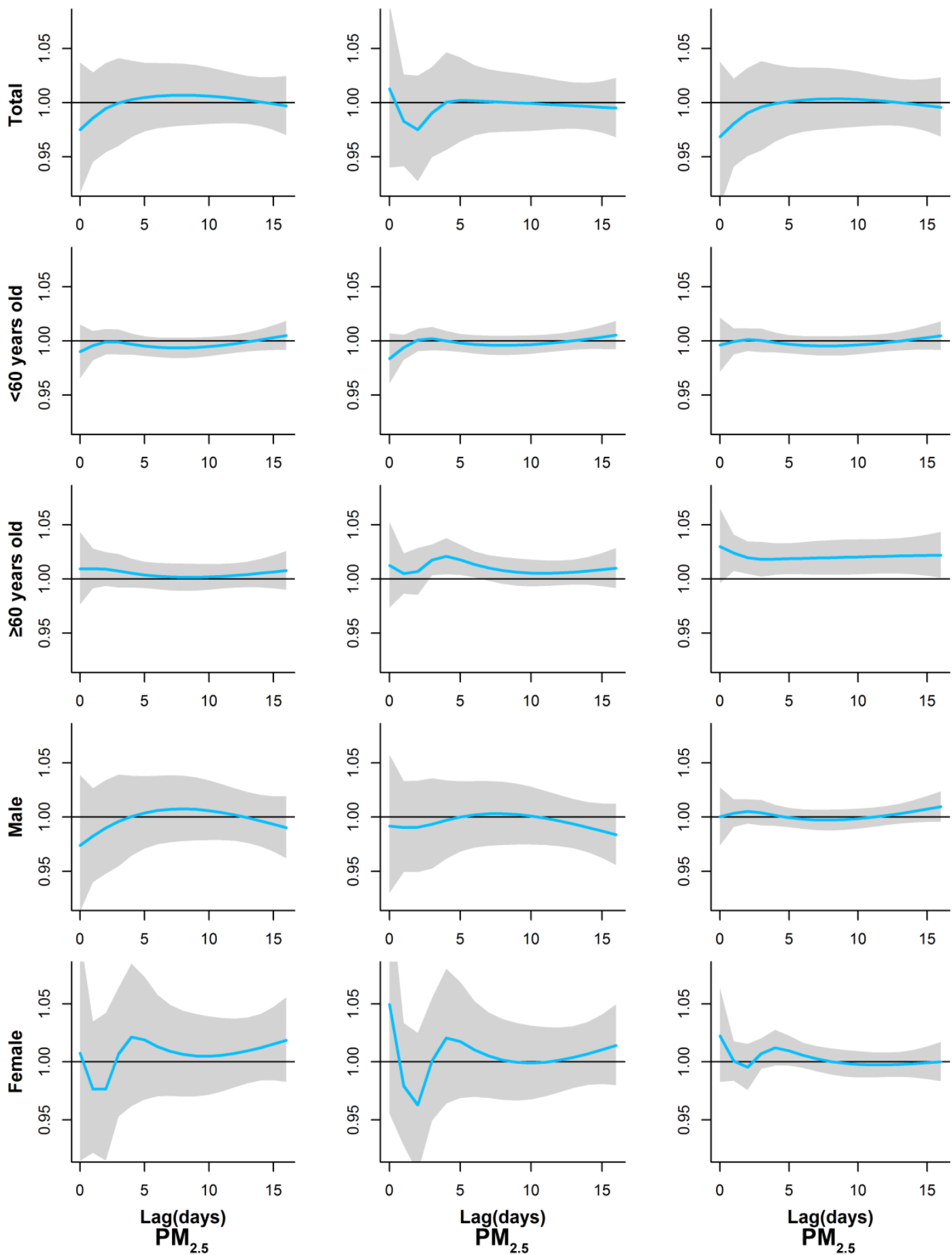

eFigure 11. Lag-specific relative risks (95\% confidence interval) in initial outpatient visits for TB per $10 \mu \mathrm{g} / \mathrm{m} 3$ increase in weekly mean concentrations of $\mathrm{PM}_{2.5}$ adjusted with $\mathrm{SO}_{2}, \mathrm{NO}_{2}$ or $\mathrm{CO}$ over lagged 16 weeks in two-pollutant models. 

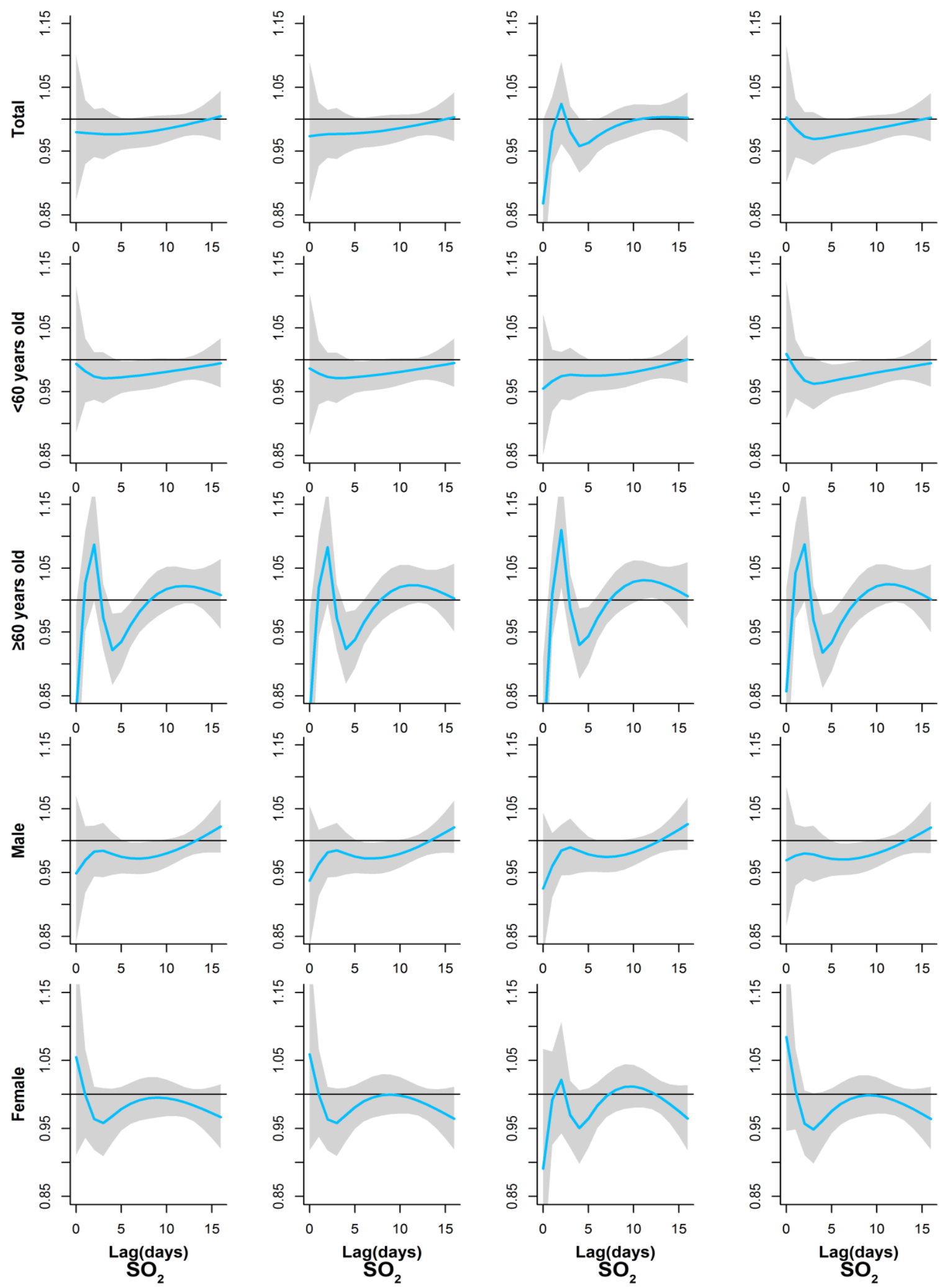

eFigure 12. Lag-specific relative risks (95\% confidence interval) in initial outpatient visits for TB per $10 \mu \mathrm{g} / \mathrm{m} 3$ increase in weekly mean concentrations of $\mathrm{SO}_{2}$ adjusted with $\mathrm{PM}_{10}, \mathrm{PM}_{2.5}, \mathrm{NO}_{2}$ or $\mathrm{CO}$ over lagged 16 weeks in two-pollutant models. 

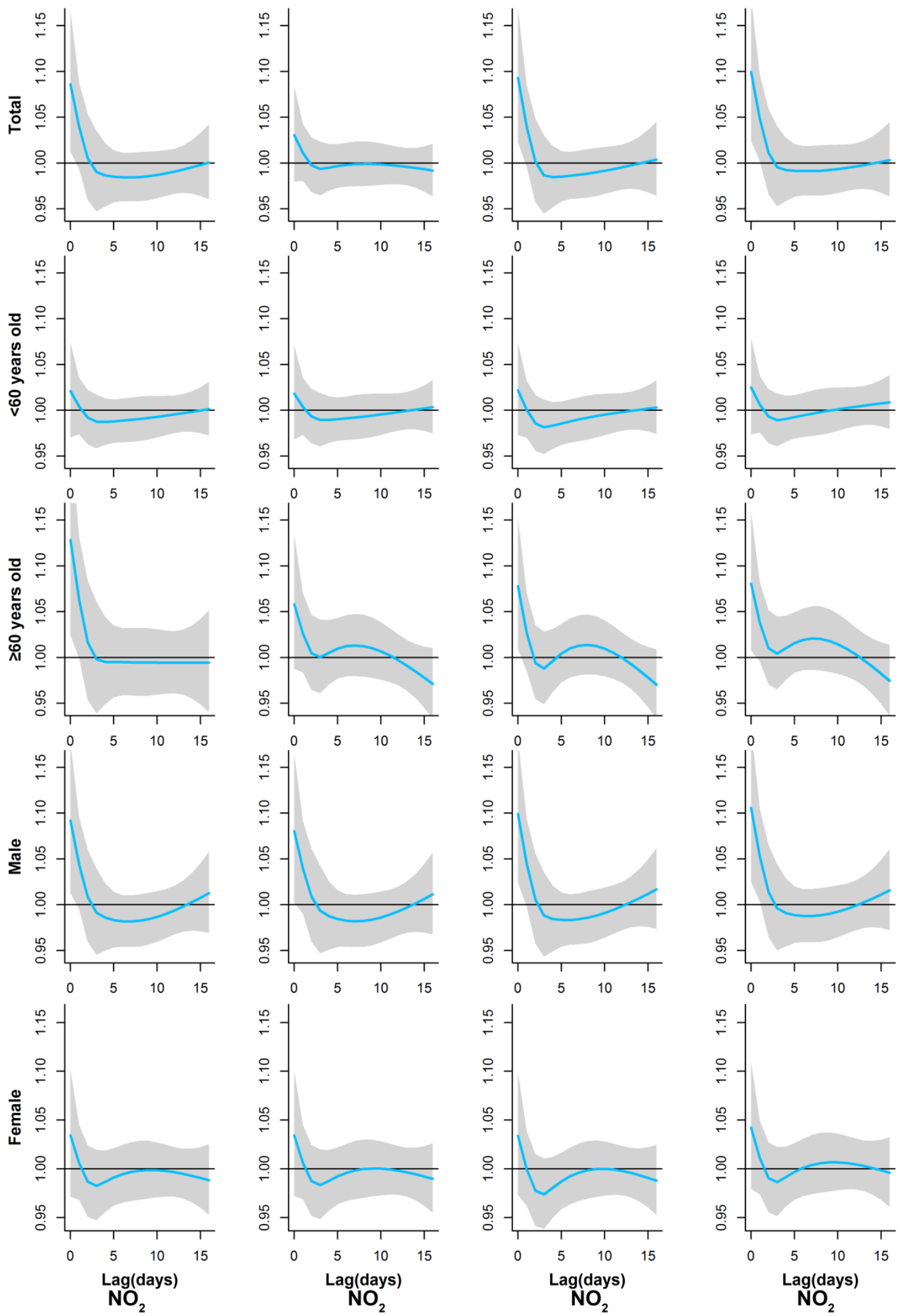

eFigure 13. Lag-specific relative risks (95\% confidence interval) in initial outpatient visits for TB per $10 \mu \mathrm{g} / \mathrm{m} 3$ increase in weekly mean concentrations of $\mathrm{NO}_{2}$ adjusted with $\mathrm{PM}_{10}, \mathrm{PM}_{2.5}, \mathrm{SO}_{2}$ or $\mathrm{CO}$ over lagged 16 weeks in two-pollutant models. 

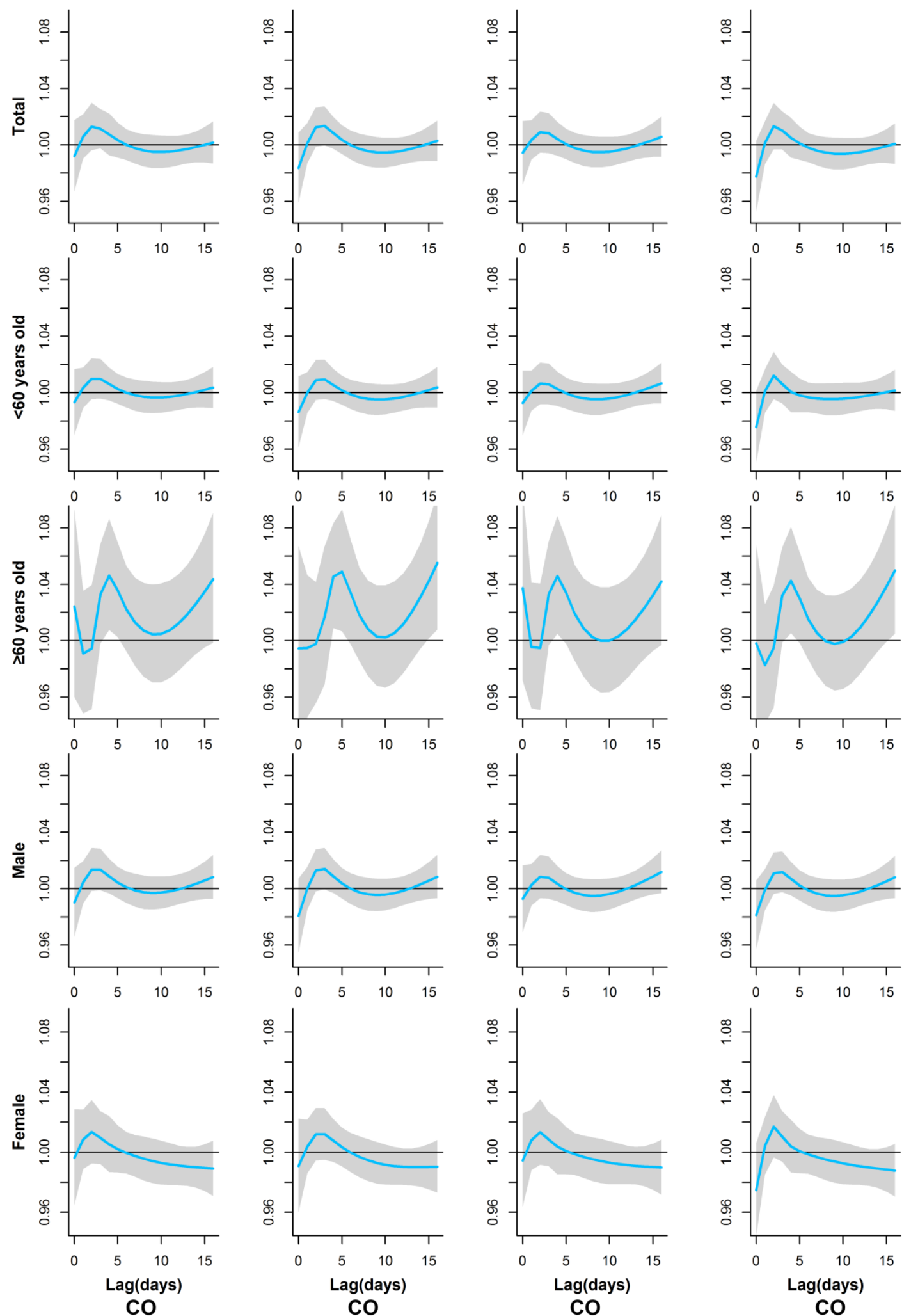

eFigure 14. Lag-specific relative risks (95\% confidence interval) in initial outpatient visits for TB per $10 \mu \mathrm{g} / \mathrm{m} 3$ increase in weekly mean concentrations of CO adjusted with $\mathrm{PM}_{10}, \mathrm{PM}_{2.5}, \mathrm{SO}_{2}$ or $\mathrm{NO}_{2}$ over lagged 16 weeks in two-pollutant models.

(3) Sensitivity analysis changing maximum lag and df in DLNM 

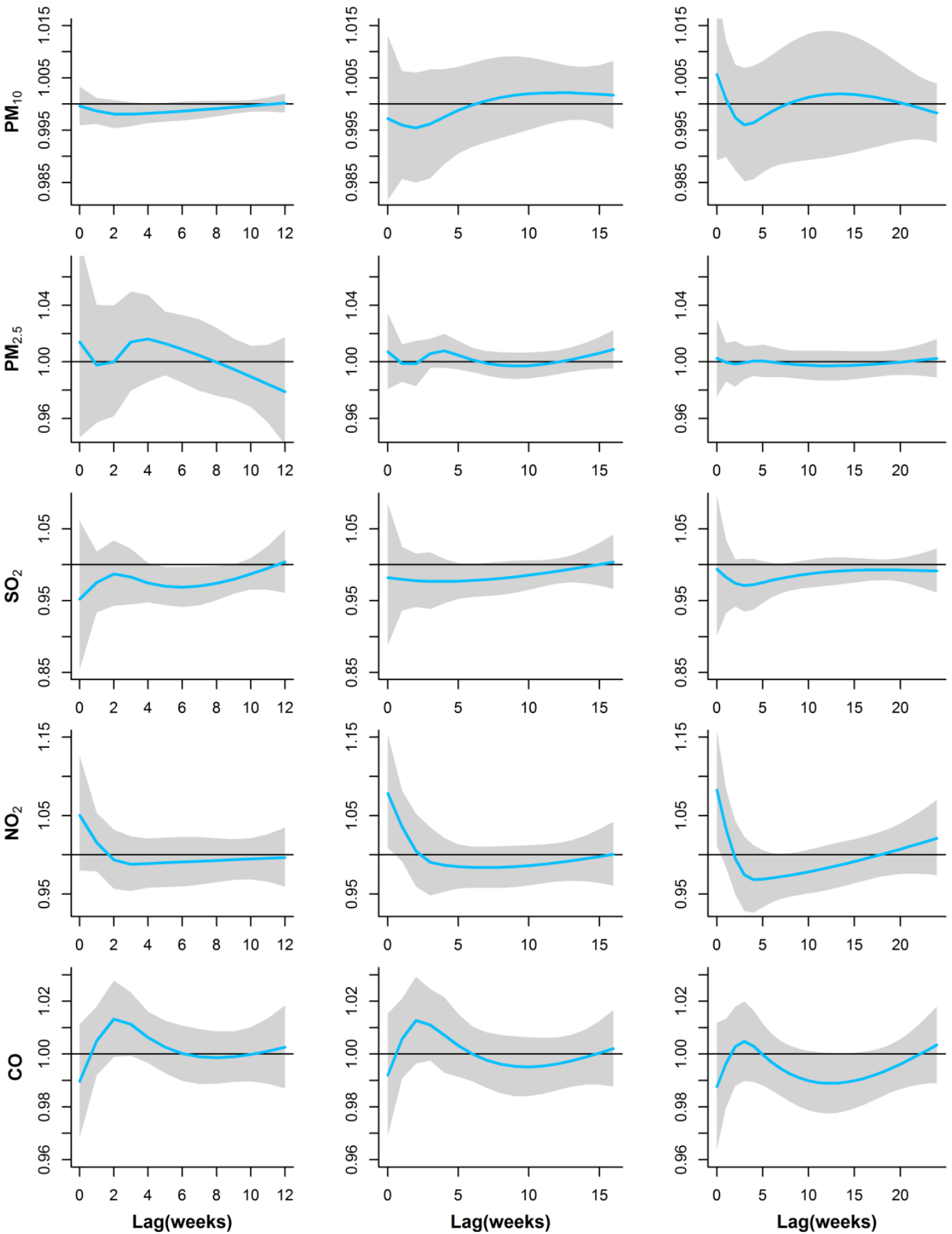

eFigure 18. Lag-specific relative risk in initial outpatient visits for TB per 10 units increase in weekly mean concentrations of air pollution over the maximum lags of 12 weeks, 16 weeks and 24 weeks in single-pollutant models. 
df $=6$
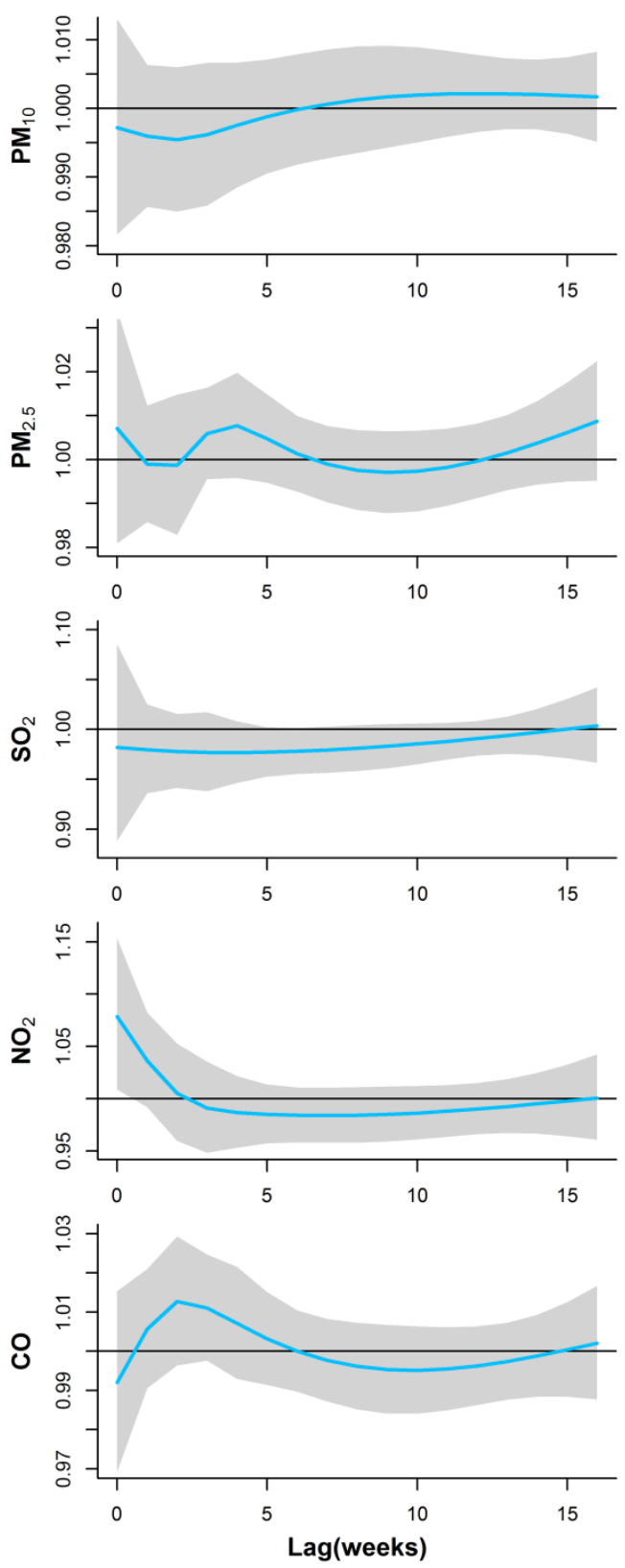

df $=7$
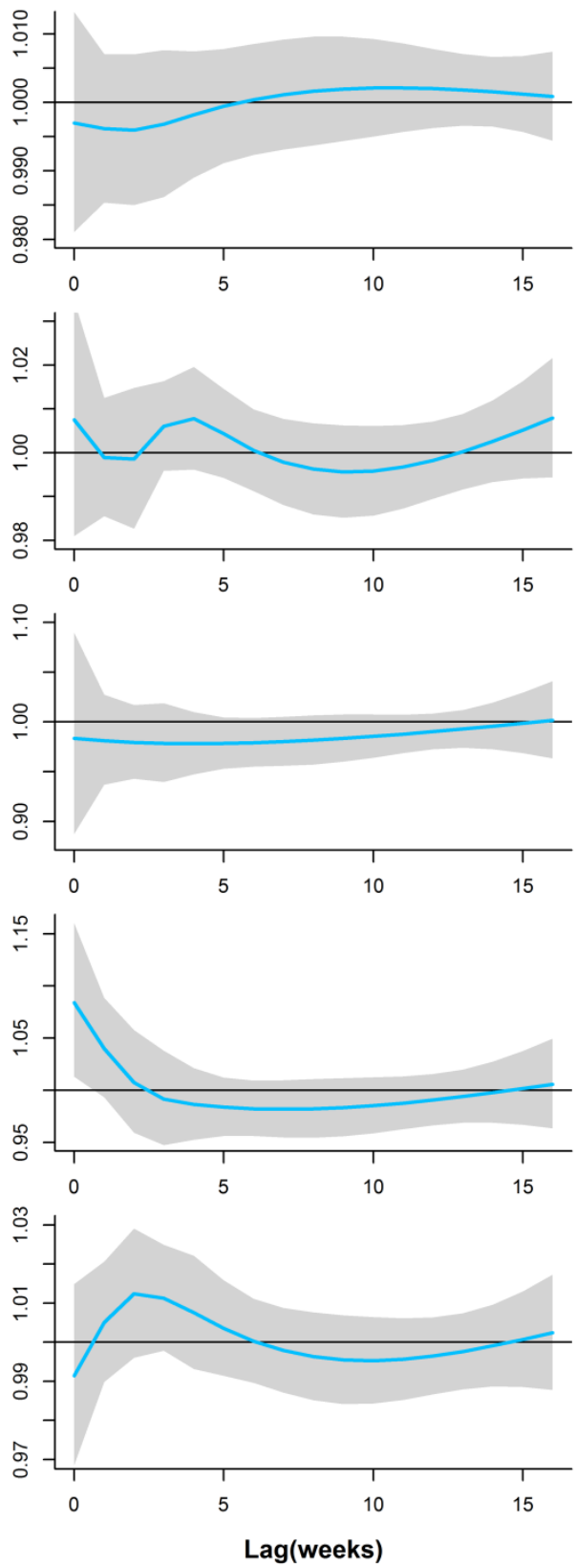

eFigure 19. Lag-specific relative risk in initial outpatient visits for TB per 10 units increase in weekly mean concentrations of air pollution over lagged 16 weeks in single-pollutant models with $6 \mathrm{df}$ and $7 \mathrm{df}$ in the natural cubic spline of time (weeks). 
df $=3$
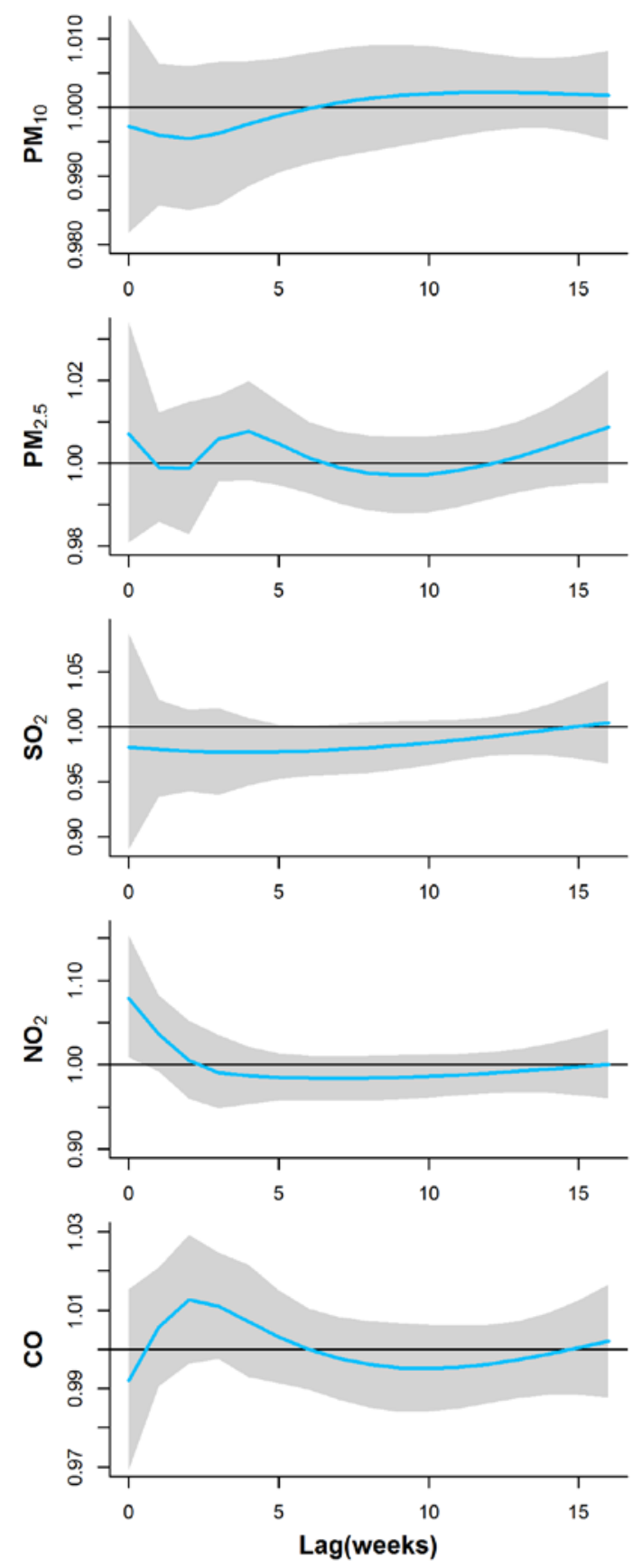

df $=4$
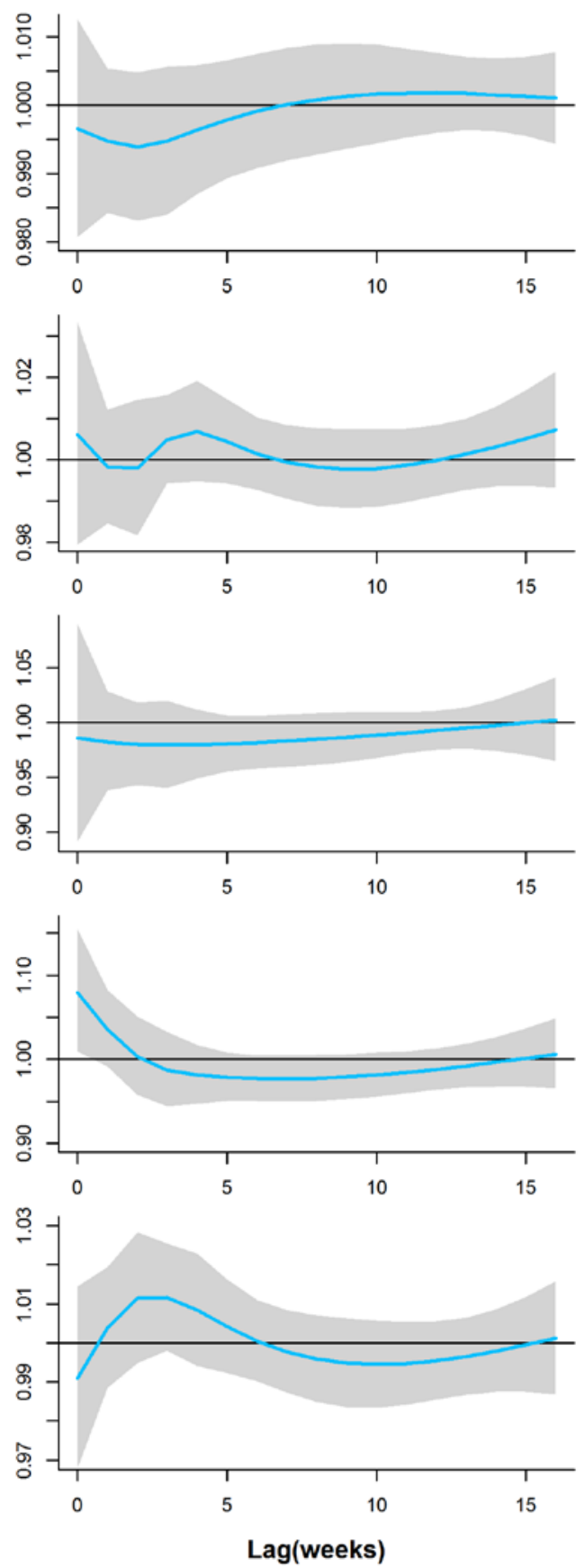

eFigure 20. Lag-specific relative risk in initial outpatient visits for TB per 10 units increase in weekly mean concentrations of air pollution over lagged 16 weeks in single-pollutant models with $3 \mathrm{df}$ and $4 \mathrm{df}$ in the natural cubic spline of meteorological factors. 


\section{REFERENCE}

1 Peng RD, Dominici F, Louis TA. Model Choice in Time Series Studies of Air Pollution and Mortality. J R Statist Soc 2006; 169: 179-203.

2 Yang X, Duan Q, Wang J, et al. Seasonal Variation of Newly Notified Pulmonary Tuberculosis Cases from 2004 to 2013 in Wuhan, China. PloS one. 2014; 9: e108369.

3 Chen F, Deng Z, Deng Y, et al. Attributable risk of ambient $\mathrm{PM}_{10}$ on daily mortality and years of life lost in Chengdu, China. Sci Total Environ 2017;581-582:426-33.

4 You S, Tong YW, Neoh KG, et al. On the association between outdoor $\mathrm{PM}_{2.5}$ concentration and the seasonality of tuberculosis for Beijing and Hong Kong. Environ Pollut 2016:218:1170-79.

5 Guo Y, Barnett AG, Pan X, et al. The impact of temperature on mortality in Tianjin, China: a case-crossover design with a distributed lag nonlinear model. Environ Health Perspect 2011; 119:1719-25.

6 Gasparrini A, Armstrong B, Kenward MG. Distributed lag non-linear models. Stat Med 2010; 29:2224-34.

7 Zhu S, Xia L, Wu J, et al. Ambient air pollutants are associated with newly diagnosed tuberculosis: A time-series study in Chengdu, China. Sci Total Environ 2018; 631-632, 47-55. 